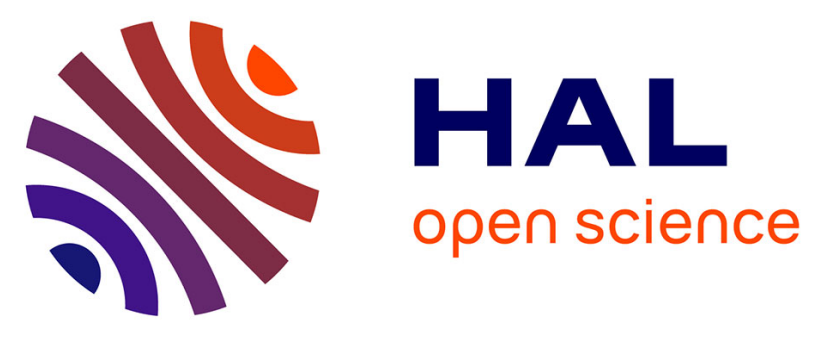

\title{
Development and evaluation of a new dietary index assessing nutrient security by aggregating probabilistic estimates of the risk of nutrient deficiency in two French adult populations
}

\author{
Marion Salomé, Emmanuelle Kesse-Guyot, Hélène Fouillet, Mathilde Touvier, \\ Serge Hercberg, Jean-François Huneau, François Mariotti
}

\section{To cite this version:}

Marion Salomé, Emmanuelle Kesse-Guyot, Hélène Fouillet, Mathilde Touvier, Serge Hercberg, et al.. Development and evaluation of a new dietary index assessing nutrient security by aggregating probabilistic estimates of the risk of nutrient deficiency in two French adult populations. British Journal of Nutrition, In press, 10.1017/S0007114520005115 . hal-03200910

\author{
HAL Id: hal-03200910 \\ https://hal.science/hal-03200910
}

Submitted on 17 Apr 2021

HAL is a multi-disciplinary open access archive for the deposit and dissemination of scientific research documents, whether they are published or not. The documents may come from teaching and research institutions in France or abroad, or from public or private research centers.
L'archive ouverte pluridisciplinaire HAL, est destinée au dépôt et à la diffusion de documents scientifiques de niveau recherche, publiés ou non, émanant des établissements d'enseignement et de recherche français ou étrangers, des laboratoires publics ou privés.

\section{(ㅇ)(1) $\$$}

Distributed under a Creative Commons Attribution - NonCommercial - NoDerivatives $\mid 4.0$ 
This is the "postprint" version, i.e. the authors' version that has been accepted for publication, of the article by Salomé et al., finally published in British Journal of Nutrition published online: 18 December 2020.

Full reference is:

Salomé, M., Kesse-Guyot, E., Fouillet, H., Touvier, M., Hercberg, S., Huneau, J., \& Mariotti, F. (2020). Development and evaluation of a new dietary index assessing nutrient security by aggregating probabilistic estimates of the risk of nutrient deficiency in two French adult populations. British Journal of Nutrition, 1-12. doi:10.1017/S0007114520005115

The edited final article can be found on the publisher website, at: $10.1017 / \mathrm{S} 0007114520005115$ 

aggregating probabilistic estimates of the risk of nutrient deficiency in two French adult

3 populations.

4

5 Marion Salomé ${ }^{1}$, Emmanuelle Kesse-Guyot ${ }^{2}$, Hélène Fouillet ${ }^{1}$, Mathilde Touvier $^{2}$, Serge

6 Hercberg $^{2}$, Jean-François Huneau ${ }^{1}$, François Mariotti ${ }^{1}$

7

$8{ }^{1}$ Université Paris-Saclay, AgroParisTech, INRAE, UMR PNCA, 75005, Paris, France

$9 \quad{ }^{2}$ Sorbonne Paris Nord University, Inserm, Inrae, Cnam, Nutritional Epidemiology Research

10 Team (EREN), Epidemiology and Statistics Research Center - University of Paris (CRESS),

11 93017, Bobigny, France

12

13 Corresponding author: François Mariotti, 16 rue Claude Bernard, 75005 Paris,

14 France, francois.mariotti@agroparistech.fr

16 Word count: 5438

17 Short title: Development of a nutrient security index

18 Key words: Nutrition, Dietary index, Nutritional security, Micronutrient deficiency 


\section{Abstract}

21 Although micronutrient deficiencies affect 2 billion people worldwide, no index focusses on

22 measuring the risk of overt nutrient deficiency. We aimed to develop an index that could capture

23 the nutrient dimension of nutritional security, a nutrient security index (SecDiet), and evaluate its

24 apparent validity. The SecDiet (range: 0-1) is based on the square-weighted average of the

25 probabilities that the intake of 12 critical nutrients exceeds the threshold value associated with a

26 risk of overt deficiency. Using adult populations from a French representative survey (INCA3,

$27 n=1,774$ ) and a large cohort (NutriNet-Santé, $n=104,382$ ), the content and construct validity of

28 the SecDiet was evaluated by estimating associations of the SecDiet with its components and

29 with socio-demographic characteristics that are known to be associated with low micronutrient

30 intakes and statuses. The SecDiet was high in the overall population $(0.93 \pm 0.09$ in INCA3) and

31 markedly skewed towards 1 (i.e. lower risk of insufficient intake). It correlated positively with its

3212 components $(r=0.17-0.78$, all $P s<0.001)$. The SecDiet was associated with monthly income

$33(P=0.002)$, perception of financial situation, professional situation, food insufficiency and security

34 statuses (all $P_{S}<0.001$ ) in the INCA3 population and with monthly income, professional situation,

35 and level of education (all $P \mathrm{~S}<0.001$ ) in the NutriNet-Santé population. Unlike a broader nutrient-

36 based quality index taken as comparison, the SecDiet mean decreased and the tail of its

37 distribution notably extended downwards in at-risk sub-populations, thus revealing its specific

38 sensitivity. The SecDiet could be used to screen sub-groups or study the determinants of

39 nutrient insecurity in large population surveys. 
41 Micronutrient deficiency is a form of malnutrition, in the same way as under-nourishment or over-

42 nourishment ${ }^{(1)}$. However, unlike the other two forms of malnutrition, it is sometimes less visible 43 and may appear in addition to other form of malnutrition, including obesity ${ }^{(2)}$. It is considered as a

44 major public health issue as it affects 2 billion people worldwide and has serious and sometimes

45 irreversible health impacts ${ }^{(3,4)}$. Even in high income countries, nutrient deficiency remains the other

46 side of the coin of the nutritional quality of the diet, and there are growing concerns with respect

47 to vulnerable sub-populations.

48 Assessing the risk of micronutrient deficiency using nutrient intake data would be an effective way

49 to estimate the risk in a population and take public health actions consequently ${ }^{(5)}$. However, to our

50 knowledge, no index currently focuses specifically on assessing the risk of developing nutritional

51 deficiency. There are many diet quality indices that assess the potential impacts of diet on the

52 health of individuals and study adherence to food-based dietary guidelines ${ }^{(6,7)}$. These indices are

53 generally based on food-based indicators and/or nutrient-based indicators ${ }^{(8)}$.

54 Increasing importance has been given to food-based indices for defining diet quality because there

55 is a growing evidence that long-term health is more realistically and confidently reflected by the

56 overall characteristics of a $\operatorname{diet}^{(9)}$. However, these scores are not focused on nutrient intake and

57 do not allow to directly study the risk of micronutrient deficiency. By contrast, nutrient-based

58 assessments remain important in terms of fundamental relationships in nutrition, and notably the

59 detection of poor diet quality due to insufficient nutrient intake, which is important for short-term

60 health.

61 Nutrient-based indices are generally based on nutrient adequacy ratios (NAR) and mean

62 adequacy ratios $(\mathrm{MAR})^{(8,10,11)}$ or on the probability of adequacy of nutrient intakes using a 63 probabilistic approach(12-15). They may be more difficult to implement than food-based indices, 
64 because they require extensive dietary records and food composition tables ${ }^{(16)}$. They need to refer

65 to recommended intakes of selected nutrients but there are different criteria that can be used to

66 define nutrient requirements and then estimate these reference values ${ }^{(13)}$. Nutrient requirements

67 are usually defined using higher nutritional criteria than those which prevent the risk of onset of

68 clinical signs of deficiency. Indeed, the requirements can be set so as to maintain a sufficient store

69 of the nutrient, or to maximize metabolic/physiological markers ${ }^{(13)}$ and may even also take account

70 of the long-term risks of developing a chronic disease ${ }^{(17)}$.

71 Therefore, existing diet quality indices are more designed to measure overall diet quality and

72 associations with long-term health outcomes rather than nutritional status and the acute risk of

73 nutrient deficiency. There is a need for such an index that aggregates risk estimates of

74 micronutrient deficiency; a nutrient security index, that uses more stringent reference values that

75 are associated with the appearance of clinical signs of deficiency. Such an indicator also appears

76 critical for studying ongoing nutritional transition which changes the risk of nutrient shortage.

77 Our objective was to develop a score that focusses on the risk of nutritional deficiency in adults,

78 by only selecting micronutrients for which a serious clinical deficiency is referenced, and using a

79 probabilistic approach to estimate the risk of developing such a deficiency. The content and

80 construct validity of this index was then assessed using data from two French surveys, one from

81 a national representative population and a second with a large number of participants which

82 offered a wide variety of sociodemographic profiles. 


\section{Methods}

\section{Population data}

85 The data used for this study came from the third Individual and National Study on Food 86 Consumption Survey (INCA3, 2014-2015) and the NutriNet-Santé cohort study (2009, ongoing).

87 The third Individual and National Study on Food Consumption Survey 3 (INCA3) is a French 88 nationwide and representative cross-sectional survey, which has been fully described 89 elsewhere ${ }^{(18)}$. INCA3 study was carried out in accordance with the Declaration of Helsinki 90 guidelines and was approved by the 'Comité Consultatif sur le Traitement de l'Information en 91 matière de Recherche dans le domaine de la Santé' (Advisory Committee on Information 92 Processing in Health Research). Verbal consent was obtained from, witnessed and formally 93 recorded for all subjects. Briefly, dietary data were collected using three non-consecutive validated 94 24-h dietary recalls over a 3-wk period. Professional investigators were responsible for collecting 95 the dietary records by telephone, and participants were not aware of the days of recall. The 96 nutrient contents of food items came from the 2016 database of the French Centre d'Information 97 sur la Qualité des Aliments (CIQUAL). Sociodemographic questionnaires were also completed, by administered face-to-face questionnaires. Under-reporters for energy intake (EI) were excluded using the Black's cut-offs based on the Goldberg method ${ }^{(19)}$. Basal metabolic rate (BMR) was estimated using Henry's equations ${ }^{(20)}$. Participants were not considered under-reporters for a ratio

101 El:BMR > PALxexp(-1.96xS/100) where PAL represents the physical activity level, and S a factor taking into account the variability of EI and BMR and depends on the number of dietary recalls.

103 The study sample was initially composed of 2,121 adults (18-79y) and after exclusion of underreporters the final sample contained 1,774 adults (749 men and 1,025 women).

105 The NutriNet-Santé study is an ongoing French web-based cohort which started in 2009 and has 106 previously been fully described elsewhere ${ }^{(21)}$. The NutriNet-Santé study is conducted in 
accordance with the Declaration of Helsinki guidelines and was approved by the Institutional

108 Review Board of the French Institute for Health and Medical Research (IRB Inserm no. 0000388FWA00005831) and the 'Commission Nationale de l'Informatique et des Libertés' (CNIL no. 908450 and 909216). Electronic informed consent is obtained from each participant (EudraCT no. 2013-000929-31). All questionnaires are completed online via a web-based interface. At

112 inclusion and every six months, participants are required to complete online three $24 \mathrm{~h}$ dietary 113 records over a 2-wk period. These web-based $24 \mathrm{~h}$ dietary records have been validated against 114 dietary records filled during an interview with a dietitian and against blood and urinary 115 biomarkers ${ }^{(22-24)}$. Portion sizes are estimated using validated photographs ${ }^{(25)}$. The nutrient 116 contents of food items come from a published food composition table ${ }^{(26)}$. As for the INCA3 study, 117 under-reporters for energy intake were excluded using the same $\operatorname{method}^{(19)}$, but basal metabolic 118 rate was estimated using Schofield's equations ${ }^{(27)}$. Participants also complete questionnaires on 119 health, sociodemographic characteristics, anthropometrics and physical activity. The sample used during this study contained 104,382 adults over 18y (22,649 men and 81,733 women) and their dietary intake referred to $24 \mathrm{~h}$ records collected over a 2-y period following inclusion in the cohort.

122 We chose to use data from these two populations in order to obtain firstly a representative sample 123 of the French population (INCA3) for SecDiet score description purposes, and secondly a 124 population where we could characterize the behaviour of this score in more deprived sub125 populations because of the large number of participants (NutriNet-Santé).

126 Development of an index assessing the nutrient Security of Diet (SecDiet)

127 The SecDiet index has been designed to assess the risk of nutrient deficiency due to insufficient intakes of nutrients. In this study, the SecDiet has been developed for an adult population. It is 129 built on the probabilistic approach ${ }^{(28)}$ and computes, at an individual level, the probability for each 130 nutrient of having an intake sufficiently high to avoid nutrient deficiency using the probability 131 distribution of the standard normal distribution of nutrient requirements, and taking into account 
132 the mean intake $y$, the day-to-day variability of intake $S D_{y}{ }^{2}$, the number of days of dietary record $133 n$, the inter-individual variability $S D_{r}{ }^{2}$ and the nutrient reference value $r^{(14,29)}$, as follows:

$$
F\left(\frac{y-r}{\sqrt{S D_{r}^{2}+\frac{S D_{y}^{2}}{n}}}\right)
$$

135 where $F(x)$ is the function returning the probability that an observation from the standard normal 136 distribution is lower than $\mathrm{x}$. The probability for a nutrient ranges from 0 to 1 , where 1 represents 137 a $100 \%$ probability that the usual intake is adequate.

138 The nutrient reference value was derived from what we defined as the 'deficiency threshold' (DT) corresponding to the minimal intake to avoid nutritional deficiency, which would therefore be the 140 minimal criterion that could be used to set the requirement for this nutrient. We assumed that at 141 an intake equal to the DT, $\sim 97.5 \%$ of the population would have an intake sufficient to avoid 142 nutritional deficiency and $\sim 2.5 \%$ would be at risk of developing a nutritional deficiency. We then 143 defined the 'average deficiency threshold' (aDT) corresponding to the intake with which $50 \%$ of 144 the population would be at risk of having a nutritional deficiency. Assuming a normal distribution 145 of the individual threshold centred at the aDT, the aDT was therefore defined as $\mathrm{DT} /(1+2 \mathrm{CV})$. The $146 \mathrm{CV}$ was assumed to be similar to the CV of the average requirement.

147 Only nutrients for which a deficiency has been described in adults due to a primary insufficient 148 intake and not secondary to a medical condition were included in the SecDiet. The inclusion of 149 nutrients and the setting of deficiency thresholds were decided after a comprehensive review of 150 the literature, notably concerning the principal nutrient recommendations in public dietary 151 guidelines ${ }^{(17,30-33)}$. The nutrients included, because of the existence of deficiency due to insufficient 152 intakes, were thus vitamin A, thiamin, riboflavin, niacin, folate, vitamin B12, vitamin C, iodine, iron, 153 selenium, zinc, calcium, and deficiency thresholds were defined for adults based on experimental 
154 or epidemiologic studies as found reported in French, European and international dietary 155 guidelines ${ }^{(30-35)}$ and meta-analyses studies ${ }^{(36-38)}$. Deficiency thresholds are usually much lower 156 than the Reference Intakes which can be used in nutrient-based indexes, because Reference 157 intakes are often based on criteria that are not easily interpretable in terms of health impact, or 158 sometimes even unrelated to biological markers (such as Adequate Intake based on observed 159 intake), whereas a deficiency threshold directly corresponds to the risk of an overt deficiency. For 160 some nutrients, the onset of clinical signs of deficiency can be related to a certain amount of 161 nutrient intake (e.g. scurvy may appear for intake of vitamin C below 10mg/day), and this intake 162 was defined as the DT. In contrast, for some other nutrients (namely, thiamine, riboflavin, niacin, 163 folate), there was not enough literature to derive a DT, therefore we defined it as the lower 164 reference nutrient intake (which is the intake covering the standard requirements of $2.5 \%$ of the 165 population). The selection of nutrients, their associated deficiency, and deficiency thresholds are 166 shown in Table 1 and described in full in Supplemental Method 1.

167 The SecDiet score was then calculated as the sum of the squares of probabilities of nutrient 168 adequacies divided by the number of nutrients included in the calculation. Squaring the 169 probabilities was chosen in order to give more weight to the lowest probabilities among those of 170 the different nutrients included in the score, the aim being to increase its sensitivity to the risk of 171 one individual component over the other that would be expected to be close to the unity. Finally, 172 the SecDiet ranges from 0 to 1 where 1 represents the lowest risk of insufficient nutrient intakes 173 leading to nutrient deficiencies.

\section{Evaluation of the validity of the SecDiet score}

175 Content validity assesses whether the index covers all dimensions of what it is supposed to 176 measure ${ }^{(39)}$. This was evaluated after a thorough review of the literature on dietary references 177 issued by the main health and food safety agencies ${ }^{(17,30-33)}$. Correlations between score 178 components and the SecDiet were evaluated, as well as between the SecDiet and total energy 
179 intake to determine whether the SecDiet was able to assess certain quality features that would be 180 independent of (energy-related) quantity.

181 Construct validity determines whether a score correctly measures what it is meant to measure, in 182 this case nutrient security. We evaluated variations of the SecDiet across various 183 sociodemographic subgroups that are known to be more prone to nutritional deficiency. These 184 subgroups were the lowest income category ${ }^{(40)}$, people with food insufficiency or food 185 insecurity ${ }^{(41,42)}$ and unemployed persons and students ${ }^{(43,44)}$. We hypothesized that the SecDiet 186 score for most individuals would be lower in these groups, which might be reflected by a lower 187 group mean and also a downwardly elongated distribution tail in these groups, compared to other 188 groups.

The sociodemographic characteristics studied were professional occupations and monthly 190 household incomes for the INCA3 and NutriNet-Santé populations and perception of financial 191 situation, food insufficiency status and food insecurity status for INCA3 population only. For the 192 present study, the professional occupation variable was rearranged into three categories: 193 unemployed people, students and other occupations (grouping those with a professional activity 194 and retired individuals). The monthly household income was calculated per consumption unit 195 using the following weighting: 1 consumption unit (CU) was attributed for the first adult in the 196 household, $0.5 \mathrm{CU}$ for other persons aged $\geq 14 \mathrm{y}$, and $0.3 \mathrm{CU}$ for children aged<14y ${ }^{(45)}$. Perception 197 of financial situation were obtained from a questionnaire designed to determine how a household 198 evaluates its financial well-being. Food security and food insufficiency statuses came from the 199 U.S. Household Food Security Survey Module (HFSSM) ${ }^{(46)}$. The food insufficiency status was 200 derived from the preliminary question in the HFSSM survey and evaluates whether a household 201 has had enough to eat during the past 12 months, while the food security status was obtained 202 from the US Household Food Security Survey Module six-item short form. 
204 The behaviour of the SecDiet score within sociodemographic characteristics was compared to that 205 of a nutrient-based diet quality index, the PANDiet score, in order to determine if the SecDiet is 206 able to capture specific dimensions of nutrient intakes that are related to nutrient security, more 207 than would a classical nutrient-based diet quality index.

208 The development and the validation of the PANDiet score is fully developed elsewhere ${ }^{(14)}$. It is 209 based on the same probabilistic method than the SecDiet but differs in the choice of nutrients, 210 nutrient reference values and computation of the final score. The probability is also calculated for 211 each nutrient but the nutrient value is mainly based on national nutrient reference intakes for 212 French adults ${ }^{(33)}$ with more nutrients included.

213 The PANDiet score is based on two sub-scores, the Adequacy Sub-score, which is the average 214 of probabilities of adequacy for 27 nutrients for which the usual intake should be above a reference 215 value, multiplied by 100 , and the Moderation Sub-score, which is the average of probabilities of 216 adequacy for 6 nutrients for which the usual intake should not exceed a reference value, multiplied

217 by 100 . The PANDiet score is the average of the Adequacy Sub-score and the Moderation Sub218 Score and ranges from 0 to 100 where a higher score indicates a better diet quality. The nutrients 219 included and their associated reference values are presented in Supplemental Method 2.

\section{Statistical analyses}

221 The weighting schemes proposed in INCA3 were used to account for the complex survey design. 222 Spearman correlation coefficients were used to assess correlations between the SecDiet score 223 and other variables. The NutriNet-Santé population was divided into deciles of SecDiet and the $1^{\text {st }}$ 224 decile of SecDiet was further stratified into deciles in order to reveal the characteristics of first ten 225 percentiles of SecDiet, corresponding to the lowest SecDiet score and hence the population the 226 most at risk of nutritional deficiency. Categorical variables are presented as percentages and 227 differences across deciles and across first ten percentiles were determined using $\mathrm{X}^{2}$ tests. 
228 Descriptive statistics (mean, SD, range, quartiles, $5^{\text {th }}$ and $95^{\text {th }}$ percentiles) were used to describe 229 the distribution of the SecDiet and the PANDiet in the population and across the sociodemographic 230 characteristics studied and presented using boxplots. Kruskal-Wallis non-parametric tests were 231 performed to assess significant differences between the SecDiet, the PANDiet and 232 sociodemographic variables. Pairwise multiple comparisons within sociodemographic variables 233 categories were assessed using the Dwass-Steel-Critchlow-Fligner (DSCF) test.

234 All statistical analyses were performed using SAS version 9.4 (SAS Institute Inc., Cary, NC, USA.). 235 Weighting schemes were considered using a weight statement. Significance was set at $\mathrm{P}<0.05$. 


\section{Distribution of the SecDiet score in study populations}

238 In the INCA3 population, components of the SecDiet were correlated to each other and with the 239 overall SecDiet ( $r=0.17$ to $r=0.78$ with the SecDiet, all $P s<0.001)$. The components with highest 240 correlation coefficients were iodine $(r=0.78)$, riboflavin $(r=0.74)$, folate and calcium $(r=0.70)$ and

241 vitamin A ( $r=0.68)$, when compared to the lowest coefficients observed for thiamin $(r=0.17)$ or 242 niacin $(r=0.20)$. The SecDiet was positively correlated with total energy intake $(r=0.44)$ and with 243 the PANDiet score $(r=0.50)$ (Supplemental Table 1).

244 The distributions of the SecDiet in the INCA3 and NutriNet-Santé populations are presented in 245 Figure 1 and were similar, with a distribution strongly skewed towards the upper bound of the 246 score (i.e. 1).

247 In the INCA3 population, the mean SecDiet score was $0.93 \pm 0.09$. The lowest probabilities of 248 adequacy were found for vitamin $A(0.89 \pm 0.18)$ and iodine $(0.90 \pm 0.15)$ (Table 2), i.e., individual 249 components among the most strongly correlated with the overall score. In the NutriNet-Santé 250 population, the mean SecDiet score was $0.96 \pm 0.06$. The lowest probability of adequacy was 251 found for iodine $(0.87 \pm 0.20)$ (Table 3$)$. In both populations, the SecDiet score was lower in women 252 than in men (0.91 vs 0.94 in INCA3 and 0.95 vs 0.97 in NutriNet-Santé, respectively).

254 Sociodemographic characteristics of individuals with a relatively low SecDiet score

255 We characterized the sociodemographic characteristics of the deciles and first ten percentiles of

256 the SecDiet in the NutriNet-Santé population (Table 4). The CV of the SecDiet was very low, 257 except for the $1^{\text {st }}$ decile $(11 \%)$ and $1^{\text {st }}$ percentile $(13 \%)$. More women and individuals who were 258 younger, had a lower level of qualifications or of monthly income were found in lower SecDiet 
score (all $P s<0.001$, except for sex across first $10^{\text {th }}$ percentiles where $P=0.465$ ). Compared to the

$26010^{\text {th }}$ decile, individuals in the $1^{\text {st }}$ decile were more often single (28.4\% vs $14.6 \%$ ) or living as an 261 unmarried couple (29.8\% vs $19.2 \%)$. Individuals in the $1^{\text {st }}$ percentile were predominantly single 262 (36.3\%). Individuals with lower SecDiet score were more likely to be unemployed (11.8\% in the $2631^{\text {st }}$ percentile, $9.1 \%$ in the $1^{\text {st }}$ decile vs $4.2 \%$ in the $10^{\text {th }}$ decile $)$, students $\left(21.9 \%\right.$ in the $1^{\text {st }}$ percentile, $26416.0 \%$ in the $1^{\text {st }}$ decile vs $4.1 \%$ in the $10^{\text {th }}$ decile $)$ and employees $\left(27.2 \%\right.$ in the $1^{\text {st }}$ percentile, $26525.2 \%$ in the $1^{\text {st }}$ decile vs $14 \%$ in the 10 th decile).

The SecDiet score of groups in which a higher risk of nutrient deficiency was expected and comparison with the PANDiet score

269 The SecDiet score was plotted according to the monthly income per household unit and the 270 professional occupation in the INCA3 and the NutriNet-Santé populations (Figure 2). In both 271 populations, the SecDiet decreased with lower monthly income. In the INCA3 population, the 272 SecDiet decreased from $0.94 \pm 0.07$ for the highest income bracket to $0.91 \pm 0.11$ for the lowest 273 income bracket $(P=0.002$, Supplemental Table 2). In the NutriNet-Santé population, the SecDiet 274 decreased from $0.97 \pm 0.05$ for the highest income bracket to $0.94 \pm 0.08$ for the lowest income 275 bracket $(P<0.001$, Supplemental Table 3). Regarding the professional situation, the SecDiet was 276 lower among the unemployed people $(0.91 \pm 0.09)$ vs other occupations $(0.93 \pm 0.09)$ but did not 277 differ significantly for students $(0.92 \pm 0.11)$ vs other occupations in the INCA3 population 278 (Supplemental Table 4). In the NutriNet-Santé population, the SecDiet score was lower among 279 the unemployed people $(0.94 \pm 0.08)$ and students $(0.93 \pm 0.08)$ compared to other occupations $280(0.96 \pm 0.06)(P<0.001)$ (Supplemental Table 5). 
The differences between the SecDiet and the PANDiet scores were studied in the INCA3 population by comparing their behaviours according to the perception of financial situation, the food insufficiency and food insecurity statutes (Figure 3).

284 Both the SecDiet and the PANDiet scores decreased with lower perception of financial situation. 285 However, the decrease was more important for the SecDiet. The difference of the SecDiet 286 between the "Financially comfortable" status $(0.94 \pm 0.08)$ and the "Can't manage without debts" 287 status $(0.85 \pm 0.14)$ represented a $9.6 \%$ decrease, whereas between the same two statutes, the 288 decrease of the PANDiet was of 2.9\% (Supplemental Table 6). Furthermore, it was important to 289 note that the distribution of the SecDiet spread downwards in subpopulations with the lowest 290 financial situations compared to the PANDiet score (Figures 3(a) and 3(b)). Indeed, the SecDiet 291 CV was $16.5 \%$ in the lowest financial situation class and $8.5 \%$ in the highest financial situation 292 class. The PANDiet and SecDiet scores were both significantly different across food insufficiency 293 status groups ( $P s<0.001)$, with higher scores for food sufficiency status compared to qualitative 294 and quantitative food insufficiency statutes (Supplemental Table 7). The SecDiet score was higher 295 for food security status $(0.93 \pm 0.08)$ compared to moderate food insecurity $(0.89 \pm 0.13)$ and 296 severe food insecurity $(0.89 \pm 0.10)$, which both had similar SecDiet score $(P<0.001)$. The PANDiet 297 score was only significantly different for moderate food insecurity (63.07 \pm 5.73$)$ compared to food 298 security $(64.53 \pm 5.73)(P=0.002)$ (Supplemental Table 8).

299 As highlighted by the boxplot representations, the main difference between the SecDiet and the 300 PANDiet score was the specific spreading of the boxplots towards lower SecDiet scores (i.e. 301 decrease in the $5^{\text {th }}$ percentile) for food insufficiency and food insecurity statutes, which was not 302 observed with the PANDiet.

\section{Discussion}


305 The aim of this study was to evaluate the validity of a new dietary index that describes the nutrient 306 security of diet, the SecDiet. This index consists in an aggregate probabilistic assessment of the 307 risk of deficiency for 12 micronutrients that are of potentially considerable importance to public 308 health. After an in-depth examination, the SecDiet displayed a good content and construct validity. 309 Unlike an overall nutrient-based diet quality index, the SecDiet is particularly sensitive to situations 310 that are known to increase nutritional insecurity.

311 We decided to include these 12 micronutrients after a review of the literature regarding the reality 312 and severity of selective deficiencies of all micronutrients ${ }^{(17,30,31,47)}$. The SecDiet includes the most 313 widespread micronutrient deficiencies, which are iron, iodine, folate, vitamin $A$ and zinc 314 deficiencies ${ }^{(3)}$. The lower reference values were defined as the minimal intake below which clinical 315 signs of deficiency might appear and were taken from international expert consensus reports. The 316 SecDiet score is therefore appropriate for use in other countries, including low- and middle-income 317 countries, because it is mostly not based on national reference values. However, the parameters 318 were based on reference values for adults so are not readily applicable to other populations such 319 as children or pregnant women. For two nutrients, namely iron and iodine, we were able to 320 recalibrate the estimation of the risk of deficiency on the national prevalence of anaemia 321 (haemoglobin $<13 \mathrm{~g} / \mathrm{dl}$ for men and $<12 \mathrm{~g} / \mathrm{dl}$ for women) ${ }^{(48)}$ and goitre ${ }^{(49)}$. Indeed, although the 322 reference values employed offer a good reflection of the minimal intake required to prevent 323 deficiency (based on data in the literature) it appears that these thresholds overestimate the risk 324 when compared to the figures regarding the actual prevalence of deficiency. To be adaptable to 325 other populations and settings, worldwide prevalence estimates for anaemia ${ }^{(50)}$ and goitre could 326 be used ${ }^{(51)}$, or estimates for the country under study, if these data are available. This approach is 327 interesting because it involves theoretical information that links individual dietary records to the 328 actual average risk estimates observed directly in the population. 
329 We found that the SecDiet score was positively correlated to all its components, but coefficients 330 of correlations revealed that all components did not make the same contribution to this score. 331 These differences indicate that some nutrients have little influence on variations of the SecDiet 332 score, presumably because current intakes in these populations are high compared to the 333 reference threshold used here to estimate the risk of overt deficiency. By contrast, other nutrients 334 were more strongly correlated with the SecDiet score and were also those with the lowest means 335 (vitamin A, riboflavin, folate, iodine and calcium), suggesting a higher risk of developing a clinical 336 deficiency of these nutrients. It appears that the SecDiet score was not independent of energy 337 intake; a higher energy intake being associated with a lower risk of developing nutritional 338 deficiency, as had been expected. The SecDiet is therefore not fully and specifically a diet quality 339 index, inasmuch as it is also associated with (energy) quantity. This was to be expected, since the 340 SecDiet is rather an aggregate estimate of the risk of deficiency.

341 Lower SecDiet scores were found in people with low monthly incomes and low perceptions of their 342 financial situation. It is widely acknowledged that poverty is one of the main causes of 343 undernutrition worldwide, and that low- and middle-income countries have the highest prevalence 344 of micronutrient deficiencies ${ }^{(3)}$. Indeed, low socioeconomic status is generally associated with poor 345 diet quality, which can be explained by several factors such as food prices and access, education 346 in nutrition or the time required for cooking ${ }^{(52)}$. Several studies have shown that adults with lower 347 socioeconomic status have lower plasma ascorbic acid concentrations ${ }^{(53)}$ and lower intakes of 348 micronutrients such as calcium and iron ${ }^{(54)}$. Here we have identified a situation of acute nutritional 349 risk in the most deprived part of the general population. The SecDiet score was also lower in 350 unemployed people and students, which is in line with studies reporting lower micronutrient intakes 351 among students ${ }^{(44,55,56)}$ and lower calcium intakes in households where the family head is 352 unemployed ${ }^{(57)}$. Low-income households are generally constrained to choose discount products 353 and energy-dense foods with low micronutrient contents ${ }^{(43,52)}$. Likewise, when characterizing 
354 individuals with a low SecDiet score, we also found more people with lower levels of education 355 and monthly income, as well as more women, younger adults and single or unmarried couples. 356 Single women with children and a low income have been reported to have lower nutrient intakes, 357 which could be secondary to giving nutritional priority to their children ${ }^{(58,59)}$.

358 As expected, the SecDiet score was lower among adults living in households suffering from food 359 insecurity or food insufficiency. Indeed, it has been seen in the US that, in food-insufficient families, 360 younger adults had lower calcium intakes, and older adults had lower intakes of iron and zinc 361 when compared to adults in food-sufficient families. Both younger and older adults had lower 362 serum concentrations of vitamin A compared to adults in food-sufficient families ${ }^{(41)}$. A study in 363 Canada found that adults in food insecure households had a higher prevalence of inadequacy for 364 vitamin $\mathrm{A}$, zinc, folate, vitamin B12 and iron but this was dependent on sex and age category ${ }^{(42)}$. 365 However, it is not surprising that low SecDiet score is associated with both low socioeconomic 366 status and food insufficiency and food insecurity because these characteristics may be correlated 367 to each other. A study in the UK found that participants living in food insecurity tended to have 368 more problems making ends meet and were often students, younger, males and had a low level 369 of education $^{(60)}$.

370 By contrast, the PANDiet score did not show the same range of variation than the SecDiet 371 regarding sociodemographic characteristics. If it also decreased with lower socioeconomic status, 372 the lower tail of the distribution did not drop as it was observed with the SecDiet. Therefore, the 373 SecDiet appears to be more specific than a broad index of dietary quality to detect situations with 374 higher risk of nutrient deficiency. The two scores were positively, but not entirely, correlated $375(r=+0.50)$, meaning that the SecDiet score is associated with overall nutrient adequacy but 376 confirming that it describes a situation that is more specific, based on fewer nutrients and another 377 type of hazard (lower threshold). 
378 The SecDiet score nevertheless has certain limitations. Because of a lack of data and scientific 379 evidence, it was necessary to derive some minimal thresholds from estimates of standard 380 requirements by defining the deficiency threshold as the intake covering requirement for only $2.5 \%$ 381 of the population. This was the case for thiamin, riboflavin, niacin, folate. These minimal intakes 382 could be refined in future when specific studies are available. Regarding the construction of the 383 score, the probabilistic approach is a method that has been recommended and previously 384 validated $^{(13,14)}$ for assessing risk of inadequacy based on nutrient requirements and intakes, but 385 we needed to assume a normal distribution around the average deficiency threshold (which is the 386 intake at which the individual risk of a nutritional deficiency would be 50\%) and to define a CV 387 corresponding to $\mathrm{CV}$ used for nutrient requirements. The distribution model and parameters 388 remains theoretical, although neither more nor less than in all generic probabilistic-based nutrient 389 risk assessment methods ${ }^{(12,13)}$. Similar to those methods, normality of the distribution of the DT is 390 assumed except for iron. It may also be important to note that this score only provides tools to 391 measure the risk of micronutrient deficiency in the general population due to insufficient intake 392 and not to a medical condition (such as malabsorption issues or being under a treatment 393 interfering with micronutrient metabolism), and therefore does not cover all possible situations 394 leading to micronutrient deficiency. Indeed, the main objective of the SecDiet was to be applied to 395 a given population so as to study the risk of micronutrient deficiency solely attributable to 396 insufficient food intake, independently of a particular health status of certain individuals.

397 In this study, dietary supplements consumption was not considered but this may not have changed 398 the observed results since, in France, it has been shown that dietary supplements consumption 399 only slightly improves nutrient adequacy ${ }^{(61)}$. Furthermore, it has been shown in the NutriNet-Santé 400 study that consumers of dietary supplements rather belonged to higher socio-professional 401 category and had lower prevalence of inadequate nutrient intake compared to non-consumers of 402 dietary supplements ${ }^{(62)}$. So dietary supplements are generally consumed by those who need it the 
least. Our results highlighted that low SecDiet score, and therefore higher risk of nutritional deficiency, was observed in individuals with lower-socioeconomic status, which are less prone to consume dietary supplements.

406 Further studies should consist in validating the criteria using data that could demonstrates the 407 associations between the SecDiet score and measurements of biomarkers or clinical signs 408 indicative of individual micronutrient deficiencies in a more disadvantaged population. 409 Furthermore, such data could be used to set a cut-off point for discriminating individuals at risk of 410 deficiency. It would also provide an opportunity to recalibrate the score so that it precisely matches 411 the population-based risk of deficiency. However, it is often more difficult to obtain data from the 412 most disadvantaged individuals in nationwide population surveys because they may be homeless, 413 unemployed or not-speaking the national language ${ }^{(54)}$. When assessing nutritional status from 414 dietary surveys, discarding under-reporters has the advantage of avoiding that nutrient 415 insufficiency is over-estimated. The fact that the SecDiet was associated with energy intake in our 416 samples confirms that underestimate of energy intake would result in a downward bias of nutrient 417 security. In the application of this method, therefore, care must be taken to minimize under418 reporting, especially in people with low energy requirement. The Goldberg/Black cutoffs/methods 419 that we used has limitation, but has been widely used and remain a standard for identifying under420 reporters. One limitation of this method is the identification of under-reporters for individuals with 421 high energy requirement ${ }^{(19)}$. This type of error is however the one that would have the least 422 implication on the bias of the SecDiet.

423 Micronutrient deficiency is also referred to as hidden hunger because unlike other types of 424 malnutrition, it is frequently less visible ${ }^{(3,5)}$ so the SecDiet might offer an effective tool to screen 425 those who are more at risk of micronutrient deficiency in a representative population and identify 426 the socioeconomic characteristics that are more predictive of nutritional insecurity. So as to further 427 validate the method, further studies could also interestingly focus on specific populations with an 
428 expected higher food and nutrition insecurity, such as for instance older adults in assisted living 429 facilities or college campus. Dedicated studies on the latter population would confirm and better 430 characterize the nutritional risk that we have identified in the large general samples in this study. 431 Lastly, this score could also be very useful when studying different diet models or simulating 432 possible future diet changes. Indeed, sustainable diets have been advocated to ensure human 433 and planetary health ${ }^{(63,64)}$, but adherence to them requires substantial dietary changes that reduce 434 the intake of certain nutrients, particularly those from animal-based foods. However, the degree 435 to which this might create a real short-term risk for health that could partly offset the benefits for 436 long-term health remains uncertain. It is therefore important to characterize the true acute risk in 437 this setting and determine detailed characteristics of the diet that modulate this risk.

438 In conclusion, we propose here a new index based on the probabilistic risk of micronutrient 439 deficiency. While the present study used data from French populations, the SecDiet could be 440 applied in other countries because it is mostly not based on national dietary requirements. We 441 were able to show that the SecDiet score was indeed associated with low socioeconomic status 442 and to identify populations with an expected higher risk of nutrient insecurity. The SecDiet would 443 therefore be a useful tool to study the risk of micronutrient deficiency in a vast representative 444 population or in more specific sub-populations in which nutritional insecurity is suspected, and it 445 might also be used as a safeguard parameter when studying prospective dietary transitions. 


\section{Acknowledgements}

447 The authors sincerely thank all the volunteers of the NutriNet-Santé cohort for their continuous

448 participation in the study. We also thank Younes Esseddik, Thi Hong Van Duong, Régis Gatibelza,

449 Jagatjit Mohinder, and Aladi Timera (computer scientists); Fabien Szabo de Elenyi, Nathalie

450 Arnault, Julien Allegre, and Laurent Bourhis (datamanager/statisticians); Cédric Agaesse

451 (dietitian); Sandrine Kamdem (physicians); and Nathalie Druesne-Pecollo (operational

452 coordinator) for their technical contribution to the NutriNet-Santé study.

\section{Financial support}

454 M Salomé's PhD fellowship is currently being funded by a research contract with Terres Univia, 455 the French Interbranch organization for plant oils and proteins. F Mariotti is the scientific leader of 456 this contract.

457 NutriNet-Santé was supported by the following public institutions: Ministère de la Santé, Santé 458 Publique France, Institut National de la Santé et de la Recherche Médicale (INSERM), Institut 459 National de la Recherche Agronomique (INRA), Conservatoire National des Arts et Métiers 460 (CNAM) and Université Sorbonne Paris Nord.

\section{Conflict of Interest}

$462 \quad$ None

\section{Authorship}

464 M.S., J-F.H., and F.M. designed the research; M.S. and E.K-G. conducted the research, analysed 465 the data and performed statistical analyses; H.F., M.T., S.H., J-F.H. and F.M. provided 466 methodological tools and support; M.S. and F.M. interpreted the results; M.S. wrote the first draft 467 of the manuscript and all authors provided critical comments on the manuscript. M.S. and F.M. 
468 have primary responsibility for the final content and all authors read and approved the final 469 manuscript. 


\section{References}

1. World Health Organization (2020) Fact sheets - Malnutrition. https://www.who.int/newsroom/fact-sheets/detail/malnutrition (accessed November 2020).

2. Kaidar-Person O, Person B, Szomstein S, et al. (2008) Nutritional Deficiencies in Morbidly Obese Patients: A New Form of Malnutrition?: Part A: Vitamins. OBES SURG 18, 870-876.

3. Bailey RL, West Jr. KP \& Black RE (2015) The Epidemiology of Global Micronutrient Deficiencies. Ann Nutr Metab 66, 22-33.

4. Ritchie H \& Roser M (2017) Micronutrient Deficiency. Our World in Data. https://ourworldindata.org/micronutrient-deficiency (accessed May 2020).

5. Muthayya S, Rah JH, Sugimoto JD, et al. (2013) The Global Hidden Hunger Indices and Maps: An Advocacy Tool for Action. PLoS ONE 8, e67860 [Noor AM, editor].

6. Wirt A \& Collins CE (2009) Diet quality - what is it and does it matter? Public Health Nutr. 12, 24732492.

7. Arvaniti F \& Panagiotakos DB (2008) Healthy Indexes in Public Health Practice and Research: A Review. Critical Reviews in Food Science and Nutrition 48, 317-327.

8. Kant AK (1996) Indexes of overal diet quality: A review. J Am Diet Assoc 96, 785-791.

9. Kant AK (2004) Dietary patterns and health outcomes. Journal of the American Dietetic Association 104, 615-635.

10. Madden JP \& Yoder MD (1971) Program Evaluation: Food Stamps and Commodity Distribution in Rural Areas of Central Pennsylvania. .

11. Jun S, Zeh MJ, Eicher-Miller HA, et al. (2019) Children's Dietary Quality and Micronutrient Adequacy by Food Security in the Household and among Household Children. Nutrients 11, 965.

12. Carriquiry AL (1999) Assessing the prevalence of nutrient inadequacy. Public Health Nutr. 2, 23-34.

13. National Research Council (1986) Nutrient Adequacy: Assessment Using Food Consumption Surveys. Washington, DC: National Academies Press.

14. Verger EO, Mariotti F, Holmes BA, et al. (2012) Evaluation of a Diet Quality Index Based on the Probability of Adequate Nutrient Intake (PANDiet) Using National French and US Dietary Surveys. PLOS ONE 7, e42155 [Cameron DW, editor].

15. Arimond M, Wiesmann D, Becquey E, et al. (2010) Simple Food Group Diversity Indicators Predict Micronutrient Adequacy of Women's Diets in 5 Diverse, Resource-Poor Settings. The Journal of Nutrition 140, 2059S-2069S.

16. Trijsburg L, Talsma EF, de Vries JHM, et al. (2019) Diet quality indices for research in low- and middle-income countries: a systematic review. Nutrition Reviews 77, 515-540. 
17. Otten JJ, Hellwig JP \& Meyers LD (editors) (2006) DRI, dietary reference intakes: the essential guide to nutrient requirements. Washington, D.C: National Academies Press.

18. Dubuisson C, Dufour A, Carrillo S, et al. (2019) The Third French Individual and National Food Consumption (INCA3) Survey 2014-2015: method, design and participation rate in the framework of a European harmonization process. Public Health Nutr. 22, 584-600.

19. Black A (2000) Critical evaluation of energy intake using the Goldberg cut-off for energy intake:basal metabolic rate. A practical guide to its calculation, use and limitations. Int J Obes 24, 1119-1130.

20. Henry C (2005) Basal metabolic rate studies in humans: measurement and development of new equations. Public Health Nutr. 8, 1133-1152.

21. Hercberg S, Castetbon K, Czernichow S, et al. (2010) The Nutrinet-Santé Study: a web-based prospective study on the relationship between nutrition and health and determinants of dietary patterns and nutritional status. BMC Public Health 10, 242.

22. Touvier M, Kesse-Guyot E, Méjean C, et al. (2011) Comparison between an interactive web-based self-administered $24 \mathrm{~h}$ dietary record and an interview by a dietitian for large-scale epidemiological studies. Br J Nutr 105, 1055-1064.

23. Lassale C, Castetbon K, Laporte F, et al. (2015) Validation of a Web-based, self-administered, nonconsecutive-day dietary record tool against urinary biomarkers. Br. J. Nutr. 113, 953-962.

24. Lassale C, Castetbon K, Laporte F, et al. (2016) Correlations between Fruit, Vegetables, Fish, Vitamins, and Fatty Acids Estimated by Web-Based Nonconsecutive Dietary Records and Respective Biomarkers of Nutritional Status. Journal of the Academy of Nutrition and Dietetics 116, 427438.e5.

25. Hercberg S, Deheeger M \& Preziosi P (2002) SU. VI. MAX. Portions alimentaires: manuel-photos pour l'estimation des quantités. Paris: Editions Polytechnica.

26. Hercberg S (Coordinator) (2005) Table de composition SU. VI. MAX des aliments. Paris: Les éditions INSERM/Economica.

27. Schofield WN (1985) Predicting basal metabolic rate, new standards and review of previous work. Hum Nutr Clin Nutr 39 Suppl 1, 5-41.

28. Institute of Medicine Food and Nutrition Board (2000) Dietary Reference Intakes: Applications in Dietary Assessment. Washington, D.C.: National Academies Press.

29. de Gavelle E, Huneau J-F \& Mariotti F (2018) Patterns of Protein Food Intake Are Associated with Nutrient Adequacy in the General French Adult Population. Nutrients 10, 226.

30. World Health Organization \& Food and Agriculture Organization of the United Nations (editors) (2004) Vitamin and mineral requirements in human nutrition. 2nd ed. Geneva : Rome: World Health Organization ; FAO. 
31. EFSA (European Food Safety Agency) (2017) Dietary Reference Values for nutrients: Summary report. 92.

32. Nordic Council of Ministers (2014) Nordic Nutrition Recommendations 2012: Integrating nutrition and physical activity. Copenhagen: Nordic Council of Ministers.

33. Anses (2016) Actualisation des repères du PNNS : élaboration des références nutritionnelles. Maisons-Alfort, France: French Agency for Food, Environmental and Occupational Health Safety (Anses).

34. World Health Organization, Food and Agriculture Organization of the United Nations \& International Atomic Energy Agency (editors) (1996) Trace elements in human nutrition and health. Geneva: World Health Organization.

35. Institute of Medicine (U.S.) \& Panel on Micronutrients (2002) Dietary reference intakes for vitamin $A$, vitamin $K$, arsenic, boron, chromium, copper, iodine, iron, manganese, molybdenum, nickel, silicon, vanadium, and zinc. Washington, D.C.: National Academy Press.

36. Wang D, Chen X-H, Fu G, et al. (2015) Calcium intake and hip fracture risk: a meta-analysis of prospective cohort studies. Int J Clin Exp Med.

37. Bolland MJ, Leung W, Tai V, et al. (2015) Calcium intake and risk of fracture: systematic review. BMJ, h4580.

38. Bischoff-Ferrari HA, Dawson-Hughes B, Baron JA, et al. (2007) Calcium intake and hip fracture risk in men and women: a meta- analysis of prospective cohort studies and randomized controlled trials1-3. Am J Clin Nutr.

39. Bland J \& Altman D (2002) Statistics Notes: Validating scales and indexes. BMJ 324, 606-607.

40. Andrieu E, Darmon N \& Drewnowski A (2006) Low-cost diets: more energy, fewer nutrients. Eur J Clin Nutr 60, 434-436.

41. Dixon LB, Winkleby MA \& Radimer KL (2001) Dietary Intakes and Serum Nutrients Differ between Adults from Food-Insufficient and Food-Sufficient Families: Third National Health and Nutrition Examination Survey, 1988-1994. The Journal of Nutrition 131, 1232-1246.

42. Kirkpatrick SI \& Tarasuk V (2008) Food Insecurity Is Associated with Nutrient Inadequacies among Canadian Adults and Adolescents. The Journal of Nutrition 138, 604-612.

43. Smed S, Tetens I, Bøker Lund T, et al. (2018) The consequences of unemployment on diet composition and purchase behaviour: a longitudinal study from Denmark. Public Health Nutr. 21, 580-592.

44. Correa-Rodríguez M, Pocovi G, Schmidt-RioValle J, et al. (2018) Assessment of dietary intake in Spanish university students of health sciences. Endocrinología, Diabetes y Nutrición 65, 265-273.

45. INSEE (Institut national de la statistique et des études économiques) Definitions, methods and quality. https://www.insee.fr/en/information/2107769. 
46. US Department of Agriculture (2012) U.S. Household Food Security Survey Module.

https://www.ers.usda.gov/topics/food-nutrition-assistance/food-security-in-the-us/survey-tools/.

47. Biesalski HK \& Grimm P (2005) Pocket atlas of nutrition. Rev. translation of 3rd German ed. Stuttgart ; New York: Thieme.

48. Equipe de Surveillance et d'épidémiologie nutritionnelle (ESEN) (2019) Étude de santé sur l'environnement, la biosurveillance, l'activité physique et la nutrition (Esteban), 2014-2016. Volet Nutrition. Chapitre Dosages biologiques : vitamines et minéraux. Saint-Maurice, France: Santé Publique France.

49. Wémeau J-L (2010) Chapitre 8. Goitres simples et nodulaires. In Les maladies de la thyroïde. Masson.

50. WHO (2015) The global prevalence of anaemia in 2011. Geneva: World Health Organization.

51. Benoist B de, Andersson M, Egli I, et al. (2004) lodine status worldwide WHO global database on iodine deficiency. Geneva: World Health Organization, Department of Nutrition for Health and Development.

52. Darmon N \& Drewnowski A (2008) Does social class predict diet quality? The American Journal of Clinical Nutrition 87, 1107-1117.

53. Shohaimi S, Bingham S, Welch A, et al. (2004) Occupational social class, educational level and area deprivation independently predict plasma ascorbic acid concentration: a cross-sectional population based study in the Norfolk cohort of the European Prospective Investigation into Cancer (EPICNorfolk). Eur J Clin Nutr 58, 1432-1435.

54. Hulshof KFAM, Brussaard JH, Kruizinga AG, et al. (2003) Socio-economic status, dietary intake and 10 y trends: the Dutch National Food Consumption Survey. Eur J Clin Nutr 57, 128-137.

55. Ghiasvand R, Khosravi Z, Mirzaeian S, et al. (2013) Assessing the micronutrient and macronutrient intakes in female students and comparing them with the set standard values. $J$ Edu Health Promot $2,1$.

56. Šatalić Z, Colić Barić I \& Keser I (2007) Diet quality in Croatian university students: Energy, macronutrient and micronutrient intakes according to gender. International Journal of Food Sciences and Nutrition 58, 398-410.

57. Winzenberg TM, Riley M, Frendin S, et al. (2005) Sociodemographic factors associated with calcium intake in premenopausal women: a cross-sectional study. Eur J Clin Nutr 59, 463-466.

58. Tarasuk VS \& Beaton GH (1999) Women's Dietary Intakes in the Context of Household Food Insecurity. The Journal of Nutrition 129, 672-679.

59. McIntyre L, Glanville NT, Raine KD, et al. (2003) Do low-income lone mothers compromise their nutrition to feed their children? Cmal 168, 686-691. 
60. Yau A, White M, Hammond D, et al. (2020) Socio-demographic characteristics, diet and health among food insecure UK adults: cross-sectional analysis of the International Food Policy Study. Public Health Nutr., 1-13.

61. Anses (2015) Avis de l'Agence nationale de sécurité sanitaire de l'alimentation, de l'environnement et du travail relatif à l'évaluation des apports en vitamines et minéraux issus de l'alimentation non enrichie, de l'alimentation enrichie et des compléments alimentaires dans la population française : estimation des apports usuels, des prévalences d'inadéquation et des risques de dépassement des limites de sécurité. Maisons-Alfort, France: French Agency for Food, Environmental and Occupational Health \& Safety.

62. Pouchieu C, Andreeva VA, Péneau S, et al. (2013) Sociodemographic, lifestyle and dietary correlates of dietary supplement use in a large sample of French adults: results from the NutriNet-Santé cohort study. Br J Nutr 110, 1480-1491.

63. Springmann M, Clark M, Mason-D'Croz D, et al. (2018) Options for keeping the food system within environmental limits. Nature 562, 519-525.

64. Willett W, Rockström J, Loken B, et al. (2019) Food in the Anthropocene: the EAT-Lancet Commission on healthy diets from sustainable food systems. The Lancet 393, 447-492. 


\section{Tables}

Table 1. Nutrients included as components in the SecDiet score and associated deficiency and threshold values.

\begin{tabular}{|c|c|c|c|c|}
\hline Nutrient & Deficiency & Threshold (DT) & $\mathrm{CV}$ & $50 \%$ of risk (aDT) \\
\hline Vitamin $A^{(30)}$ & Xerophtalmia & $300 \mu \mathrm{g} R E$ or $270 \mu \mathrm{g} \mathrm{RE}$ & $15 \%$ & $231 \mu \mathrm{g}$ RE or $208 \mu \mathrm{g}$ RE \\
\hline Thiamin*(31) & Beriberi & $0.18 \mathrm{mg} / 1000 \mathrm{kcal}$ & $20 \%$ & $0.13 \mathrm{mg} / 1000 \mathrm{kcal}$ \\
\hline Riboflavin*(31) & Ariboflavinosis & $1.0 \mathrm{mg}$ & $10 \%$ & $0.83 \mathrm{mg}$ \\
\hline Niacin $\star(31)$ & Pellagra & $4.35 \mathrm{mg} \mathrm{NE} / 1000 \mathrm{kcal}$ & $10 \%$ & $3.63 \mathrm{NE} / 1000 \mathrm{kcal}$ \\
\hline Folate ${ }^{\star(31)}$ & Megaloblastic anaemia & $175 \mu \mathrm{g}$ & $15 \%$ & $135 \mu \mathrm{g}$ \\
\hline Vitamin B12(32) & Megaloblastic anaemia & $1 \mu \mathrm{g}$ & $15 \%$ & $0.77 \mu \mathrm{g}$ \\
\hline Vitamin $C^{(30)}$ & Scurvy & $10 \mathrm{mg}$ & $10 \%$ & $8.3 \mathrm{mg}$ \\
\hline lodine $^{\dagger(31)}$ & Goitre & $150 \mu \mathrm{g}$ & $20 \%$ & $107 \mu \mathrm{g}$ \\
\hline Selenium ${ }^{(34)}$ & Keshan disease & $21 \mu \mathrm{g}$ or $16 \mu \mathrm{g}$ & $15 \%$ & $16.2 \mu \mathrm{g}$ or $12.3 \mu \mathrm{g}$ \\
\hline Bioavailable iron ${ }^{\dagger(33)}$ & Anaemia & $1.74 \mathrm{mg}^{\ddagger}$ & $40 \%$ & $0.95 \mathrm{mg}^{\dagger}$ \\
\hline Bioavailable zinc ${ }^{(35)}$ & Zinc deficiency & $1.6 \mathrm{mg}$ or $1.3 \mathrm{mg}$ & $15 \%$ & $1.23 \mathrm{mg}$ or $1.0 \mathrm{mg}$ \\
\hline Calcium ${ }^{(36-38)}$ & Fracture risk (long-term) & $500 \mathrm{mg}$ & $15 \%$ & $385 \mathrm{mg}$ \\
\hline
\end{tabular}

DT, deficiency threshold; CV, coefficient of variation of the individual threshold; aDT, average deficiency threshold; RE, retinol equivalent; NE, niacin equivalent; EAR, Estimated Average Requirement.

* Because of insufficient data to define an intake at which clinical signs of deficiency may appear for these nutrients, the thresholds were defined as the intake covering the requirements of $2.5 \%$ of the population, defined as EAR(1-2CV) (see Supplemental Table 1).

${ }^{\dagger}$ These thresholds parameters were then further corrected to calibrate the estimated average risk using figures for the national prevalence of goitre for iodine and of anaemia for iron. For iodine, the recalibrated DT was set at $100 \mu \mathrm{g}$ and the aDT at $71.3 \mu \mathrm{g}$. For iron, the recalibrated DT was set at $0.70 \mathrm{mg}$ and the aDT at 0.38 (see Supplemental Method 1).

₹ This value applies to men and non-menstruating women. Requirements for menstruating women were estimated by considering menstrual losses using a Monte-Carlo simulation (see Supplemental Method 1). 
Table 2. SecDiet statistics and probabilities of adequacies for nutrients in the French adult population from the INCA3 survey $(n=1,774)$.

\begin{tabular}{|c|c|c|c|c|c|c|c|c|c|c|c|c|}
\hline & \multicolumn{4}{|c|}{ All $(n=1,774)$} & \multicolumn{4}{|c|}{ Men $(n=749)$} & \multicolumn{4}{|c|}{ Women $(n=1,025)$} \\
\hline & Mean & SD & Median & Q1-Q3 & Mean & SD & Median & Q1-Q3 & Mean & SD & Median & Q1-Q3 \\
\hline SecDiet $(0-1)$ & 0.93 & 0.09 & 0.96 & $0.90-0.99$ & 0.94 & 0.08 & 0.97 & $0.93-0.99$ & 0.91 & 0.09 & 0.95 & $0.87-0.99$ \\
\hline \multicolumn{13}{|c|}{ Probabilities of adequacy of the SecDiet score (0-1) } \\
\hline Vitamin A & 0.89 & 0.18 & 0.96 & $0.87-1.00$ & 0.89 & 0.21 & 0.96 & $0.87-1.00$ & 0.90 & 0.16 & 0.97 & $0.86-1.00$ \\
\hline Thiamin & 1.00 & 0.01 & 1.00 & $1.00-1.00$ & 1.00 & 0.01 & 1.00 & $1.00-1.00$ & 1.00 & 0.01 & 1.00 & $1.00-1.00$ \\
\hline Riboflavin & 0.94 & 0.12 & 1.00 & $0.94-1.00$ & 0.96 & 0.11 & 1.00 & $0.97-1.00$ & 0.92 & 0.13 & 0.99 & $0.89-1.00$ \\
\hline Niacin & 1.00 & 0.01 & 1.00 & $1.00-1.00$ & 1.00 & 0.01 & 1.00 & $1.00-1.00$ & 1.00 & 0.01 & 1.00 & $1.00-1.00$ \\
\hline Folate & 0.94 & 0.13 & 1.00 & $0.94-1.00$ & 0.96 & 0.11 & 1.00 & $0.97-1.00$ & 0.92 & 0.13 & 0.99 & $0.89-1.00$ \\
\hline Vitamin B12 & 0.97 & 0.05 & 1.00 & $0.96-1.00$ & 0.98 & 0.05 & 1.00 & $0.97-1.00$ & 0.97 & 0.06 & 0.99 & $0.95-1.00$ \\
\hline Vitamin C & 0.97 & 0.05 & 1.00 & $0.97-1.00$ & 0.98 & 0.05 & 1.00 & $0.98-1.00$ & 0.97 & 0.05 & 0.99 & $0.96-1.00$ \\
\hline Iodine & 0.90 & 0.15 & 0.97 & $0.87-1.00$ & 0.93 & 0.14 & 0.98 & $0.92-1.00$ & 0.87 & 0.16 & 0.94 & $0.82-1.00$ \\
\hline Selenium & 0.99 & 0.02 & 1.00 & $1.00-1.00$ & 0.99 & 0.02 & 1.00 & $1.00-1.00$ & 0.99 & 0.02 & 1.00 & $1.00-1.00$ \\
\hline Iron & 0.97 & 0.07 & 0.99 & $0.96-1.00$ & 0.98 & 0.05 & 1.00 & $0.98-1.00$ & 0.95 & 0.08 & 0.99 & $0.94-1.00$ \\
\hline Zinc & 0.99 & 0.05 & 1.00 & $1.00-1.00$ & 0.99 & 0.05 & 1.00 & $1.00-1.00$ & 0.98 & 0.05 & 1.00 & $0.99-1.00$ \\
\hline Calcium & 0.94 & 0.14 & 0.99 & $0.94-1.00$ & 0.95 & 0.13 & 1.00 & $0.96-1.00$ & 0.92 & 0.15 & 0.99 & $0.90-1.00$ \\
\hline
\end{tabular}


Table 3. SecDiet statistics and probabilities of adequacies for nutrients in the French adult population from the NutriNet-Santé study $(n=104,382)$.

\begin{tabular}{|c|c|c|c|c|c|c|c|c|c|c|c|c|}
\hline & \multicolumn{4}{|c|}{ All $(n=104,382)$} & \multicolumn{4}{|c|}{ Men $(n=22,649)$} & \multicolumn{4}{|c|}{ Women $(n=81,733)$} \\
\hline & Mean & $\mathrm{SD}$ & Median & Q1-Q3 & Mean & SD & Median & Q1-Q3 & Mean & SD & Median & Q1-Q3 \\
\hline SecDiet (0-1) & 0.96 & 0.06 & 0.98 & $0.95-0.99$ & 0.97 & 0.05 & 0.99 & $0.97-1.00$ & 0.95 & 0.07 & 0.98 & $0.94-0.99$ \\
\hline \multicolumn{13}{|c|}{ Probabilities of adequacy of the SecDiet score (0-1) } \\
\hline Vitamin A & 0.98 & 0.06 & 1.00 & $0.99-1.00$ & 0.98 & 0.06 & 1.00 & $0.99-1.00$ & 0.98 & 0.06 & 1.00 & $0.99-1.00$ \\
\hline Thiamin & 1.00 & 0.00 & 1.00 & $1.00-1.00$ & 1.00 & 0.00 & 1.00 & $1.00-1.00$ & 1.00 & 0.00 & 1.00 & $1.00-1.00$ \\
\hline Riboflavin & 0.96 & 0.12 & 1.00 & $0.99-1.00$ & 0.98 & 0.08 & 1.00 & $1.00-1.00$ & 0.96 & 0.13 & 1.00 & $0.99-1.00$ \\
\hline Niacin & 1.00 & 0.02 & 1.00 & $1.00-1.00$ & 1.00 & 0.02 & 1.00 & $1.00-1.00$ & 1.00 & 0.02 & 1.00 & $1.00-1.00$ \\
\hline Folate & 0.97 & 0.11 & 1.00 & $0.99-1.00$ & 0.98 & 0.08 & 1.00 & $1.00-1.00$ & 0.96 & 0.11 & 1.00 & $0.99-1.00$ \\
\hline Vitamin B12 & 0.98 & 0.08 & 1.00 & $0.99-1.00$ & 0.98 & 0.07 & 1.00 & $0.99-1.00$ & 0.98 & 0.08 & 1.00 & $0.98-1.00$ \\
\hline Vitamin C & 0.99 & 0.03 & 1.00 & $1.00-1.00$ & 0.99 & 0.04 & 1.00 & $1.00-1.00$ & 0.99 & 0.03 & 1.00 & $1.00-1.00$ \\
\hline Iodine & 0.87 & 0.20 & 0.94 & $0.84-0.99$ & 0.91 & 0.16 & 0.97 & $0.90-1.00$ & 0.85 & 0.21 & 0.93 & $0.83-0.99$ \\
\hline Selenium & 1.00 & 0.02 & 1.00 & $1.00-1.00$ & 1.00 & 0.02 & 1.00 & $1.00-1.00$ & 1.00 & 0.02 & 1.00 & $1.00-1.00$ \\
\hline Iron & 0.99 & 0.04 & 1.00 & $0.99-1.00$ & 0.99 & 0.03 & 1.00 & $1.00-1.00$ & 0.99 & 0.04 & 1.00 & $0.99-1.00$ \\
\hline Zinc & 1.00 & 0.02 & 1.00 & $1.00-1.00$ & 1.00 & 0.03 & 1.00 & $1.00-1.00$ & 1.00 & 0.02 & 1.00 & $1.00-1.00$ \\
\hline Calcium & 0.97 & 0.11 & 1.00 & $0.99-1.00$ & 0.98 & 0.09 & 1.00 & $1.00-1.00$ & 0.97 & 0.11 & 1.00 & $0.99-1.00$ \\
\hline
\end{tabular}


Table 4. Sociodemographic characteristics according to deciles $\left(1^{\text {st }}, 5^{\text {th }}, 10^{\text {th }}\right)$ and lower percentiles $\left(1^{\text {st }}, 5^{\text {th }}, 10^{\text {th }}\right)$ of the SecDiet score in the French adult population from the NutriNetSanté study $(n=104,382)$.

\begin{tabular}{|c|c|c|c|c|c|c|c|c|}
\hline \multirow[b]{3}{*}{ SecDiet $^{*}$} & \multicolumn{4}{|c|}{ Deciles of SecDiet } & \multicolumn{4}{|c|}{ Percentiles of SecDiet } \\
\hline & $\begin{array}{c}\text { 1st decile } \\
(n=10,438)\end{array}$ & $\begin{array}{c}\text { 5th decile } \\
(n=10,438)\end{array}$ & $\begin{array}{l}\text { 10th decile } \\
(n=10,438)\end{array}$ & $\mathrm{P}^{\dagger}$ & $\begin{array}{c}1 \text { 1st } \\
\text { percentile } \\
(n=1,043)\end{array}$ & $\begin{array}{c}\text { 5th } \\
\text { percentile } \\
(\mathrm{n}=1,044)\end{array}$ & $\begin{array}{c}\text { 10th } \\
\text { percentile } \\
(n=1,043)\end{array}$ & $\mathrm{P}^{\ddagger}$ \\
\hline & $\begin{array}{c}0.80 \pm 0.09 \\
11.25 \%\end{array}$ & $\begin{array}{c}0.98 \pm 0.00 \\
0.00 \%\end{array}$ & $\begin{array}{c}1.00 \pm 0.00 \\
0.00 \%\end{array}$ & & $\begin{array}{c}0.60 \pm 0.08 \\
13.33 \%\end{array}$ & $\begin{array}{c}0.82 \pm 0.01 \\
1.22 \%\end{array}$ & $\begin{array}{c}0.88 \pm 0.00 \\
0.00 \%\end{array}$ & \\
\hline Sex, \% & & & & $<0.001$ & & & & 0.465 \\
\hline Men & 13.81 & 20.37 & 35.47 & & 14.67 & 13.22 & 15.72 & \\
\hline Women & 86.19 & 79.63 & 64.53 & & 85.33 & 86.78 & 84.28 & \\
\hline Age group, $\%$ & & & & $<0.001$ & & & & $<0.001$ \\
\hline$<30 y$ & 42.29 & 25.39 & 15.59 & & 53.50 & 43.01 & 37.97 & \\
\hline $30-45 y$ & 30.03 & 29.72 & 29.48 & & 26.85 & 29.98 & 29.72 & \\
\hline $45-60 y$ & 18.79 & 26.94 & 31.44 & & 13.52 & 19.25 & 21.67 & \\
\hline$>60 y$ & 8.89 & 17.95 & 23.49 & & 6.14 & 7.76 & 10.64 & \\
\hline Matrimonial status, \% & & & & $<0.001$ & & & & $<0.001$ \\
\hline Single & 28.38 & 17.47 & 14.59 & & 36.34 & 26.82 & 24.93 & \\
\hline Married & 32.07 & 47.84 & 56.65 & & 22.91 & 33.43 & 35.09 & \\
\hline Unmarried couple & 29.81 & 24.50 & 19.18 & & 30.78 & 30.36 & 30.49 & \\
\hline Widowed & 1.17 & 1.87 & 2.14 & & 0.96 & 0.77 & 1.05 & \\
\hline Not available & 0.01 & 0.02 & 0.02 & & 0.10 & 0.00 & 0.00 & \\
\hline Level of qualifications, $\%$ & & & & $<0.001$ & & & & $<0.001$ \\
\hline Secondary education & 21.66 & 18.80 & 18.44 & & 26.54 & 20.64 & 19.56 & \\
\hline Bachelor's degree & 23.27 & 17.52 & 14.13 & & 27.40 & 22.95 & 21.77 & \\
\hline Higher education & 55.07 & 63.68 & 67.43 & & 46.06 & 56.41 & 58.67 & \\
\hline Monthly income per household unit & & & & $<0.001$ & & & & $<0.001$ \\
\hline$<€ 900 €$ & 20.42 & 9.54 & 6.27 & & 27.04 & 20.50 & 17.55 & \\
\hline$€ 900-1200 €$ & 8.46 & 6.47 & 5.27 & & 8.44 & 8.14 & 7.86 & \\
\hline$€ 1200-1800 €$ & 25.19 & 24.71 & 24.77 & & 23.78 & 27.87 & 25.89 & \\
\hline$€ 1800-2300 €$ & 11.50 & 14.02 & 15.05 & & 7.96 & 10.54 & 11.89 & \\
\hline$€ 2300-2700 €$ & 6.18 & 9.03 & 10.40 & & 4.31 & 5.75 & 7.57 & \\
\hline$€ 2700-3700 €$ & 8.47 & 14.37 & 17.25 & & 6.90 & 8.24 & 9.88 & \\
\hline$>€ 3700 €$ & 4.91 & 9.80 & 12.09 & & 3.84 & 4.02 & 5.66 & \\
\hline Not available & 14.89 & 12.06 & 8.89 & & 17.74 & 14.94 & 13.71 & \\
\hline Occupational categories & & & & $<0.001$ & & & & $<0.001$ \\
\hline Farmer & 0.19 & 0.22 & 0.46 & & 0.10 & 0.29 & 0.38 & \\
\hline Managerial staff & 15.97 & 23.41 & 25.82 & & 12.18 & 15.04 & 18.98 & \\
\hline Self-employed & 2.26 & 1.69 & 1.45 & & 1.73 & 2.39 & 1.92 & \\
\hline Intermediate profession & 14.16 & 17.30 & 18.34 & & 9.78 & 15.42 & 16.20 & \\
\hline Student & 16.00 & 8.02 & 4.09 & & 21.86 & 16.09 & 13.14 & \\
\hline Retired & 8.53 & 18.16 & 25.36 & & 5.56 & 7.38 & 10.64 & \\
\hline Unemployed people & 9.08 & 5.91 & 4.20 & & 11.79 & 9.96 & 8.63 & \\
\hline Other without occupation & 6.70 & 6.16 & 4.84 & & 7.29 & 6.99 & 6.71 & \\
\hline Other non-specified & 0.19 & 0.10 & 0.04 & & 0.29 & 0.19 & 0.10 & \\
\hline Not available & 0.06 & 0.04 & 0.00 & & 0.00 & 0.10 & 0.10 & \\
\hline
\end{tabular}

${ }^{*}$ Mean $\pm \mathrm{SD}, \mathrm{CV}$

${ }^{\dagger} P$ values are from $X^{2}$ test between deciles of SecDiet.

${ }^{\ddagger} P$ values are from $X^{2}$ test between first ten percentiles of SecDiet. 


\section{Figure legends}
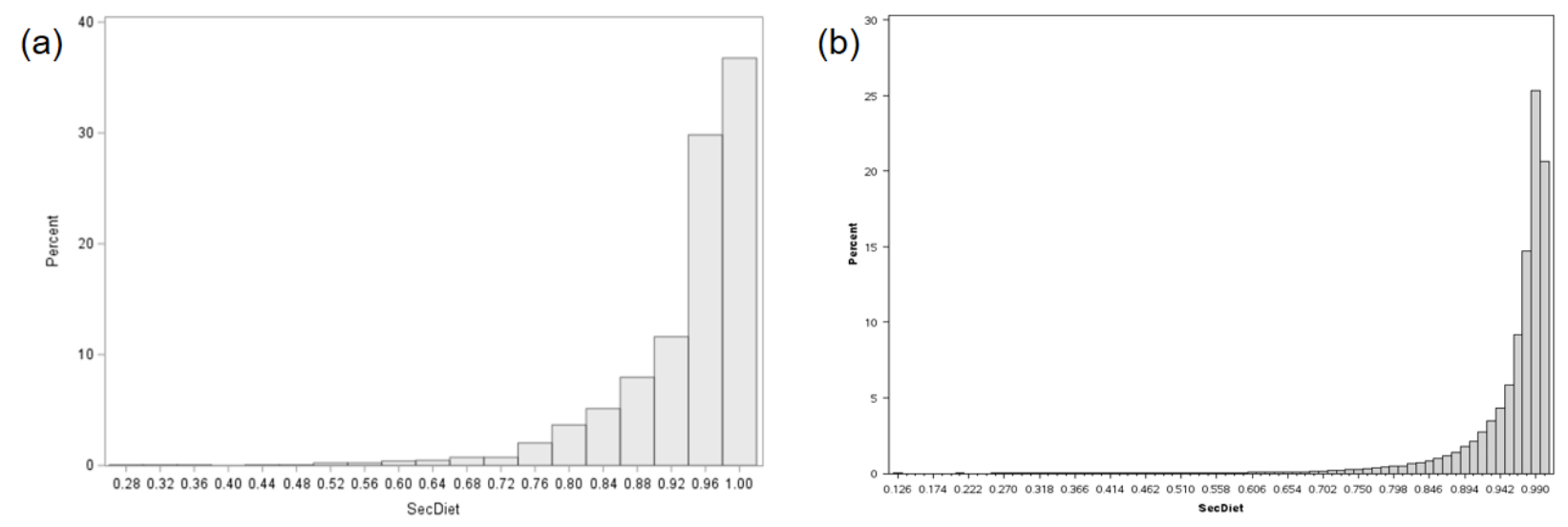

Figure 1. Distribution of the SecDiet score in (a) the INCA3 population $(n=1,774)$ and (b) the NutriNet-Santé population ( $n=104,382)$.
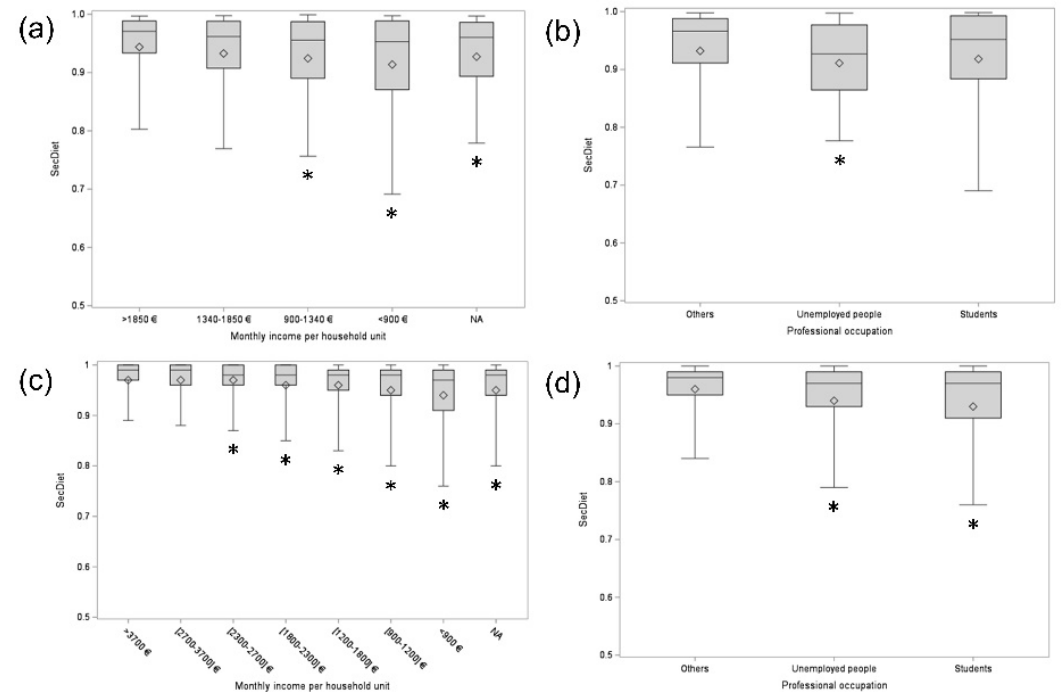

Figure 2. SecDiet score according to monthly income per household unit ((a) and (c)) and professional occupation ((b) and (d)) in the INCA3 population $(n=1,774)$ and the NutriNet-Santé population ( $n=104,382)$, respectively. * Significantly different from the reference (">1850€" or ">3700€" respectively for monthly income per household unit in the INCA3 population or the NutriNet-Santé population, "Others occupation" for professional occupation) assessed by DwassSteel-Critchlow-Fligner (DSCF) test for pairwise multiple comparisons (significance was set at $\mathrm{P}<0.05)$. NA, not available. 
(a)

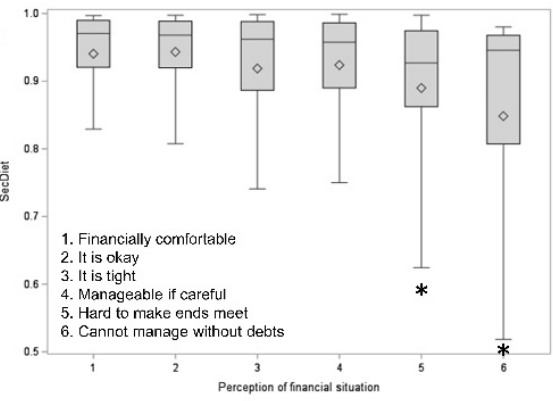

(c)

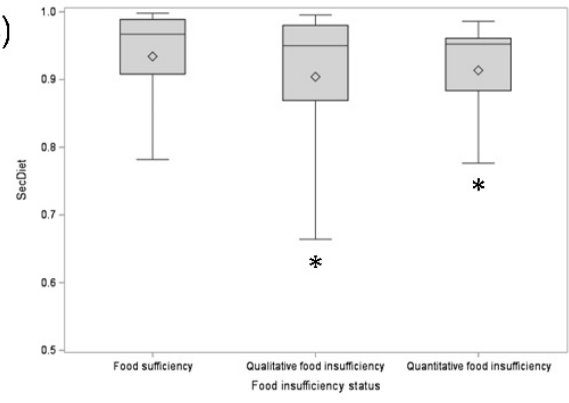

(e)

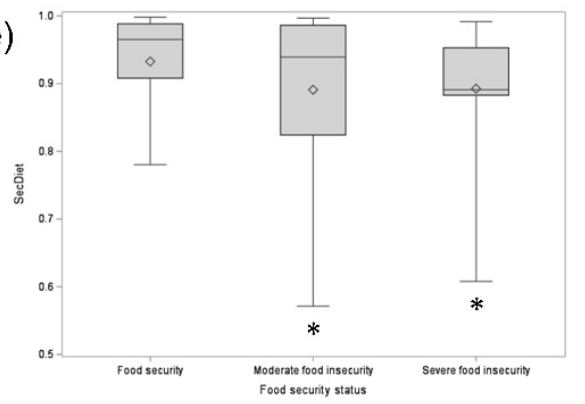

(b)

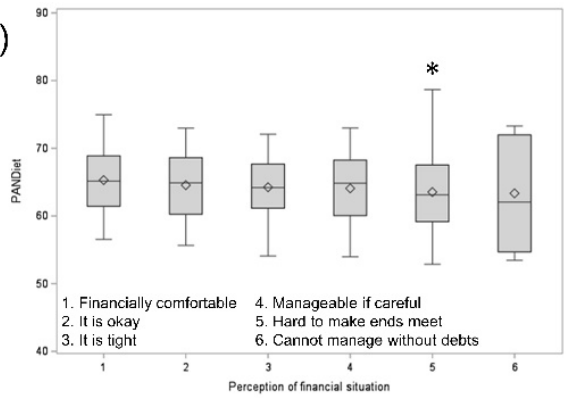

(d)

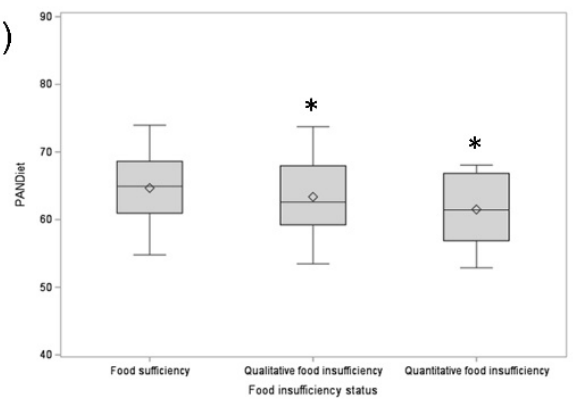

(f)

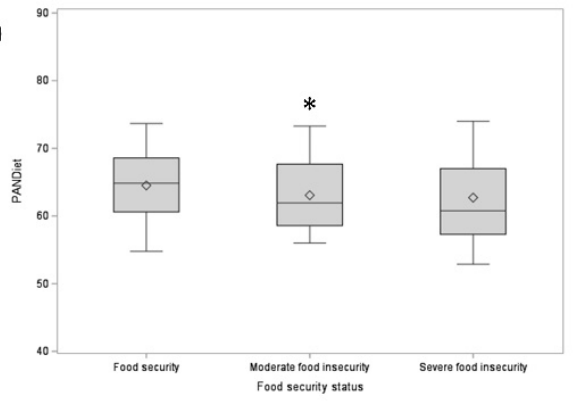

Figure 3. (a) SecDiet and (b) PANDiet scores according to the perception of financial situation; (c) SecDiet and (d) PANDiet scores according to food insufficiency status; (e) SecDiet and (f) PANDiet scores according to food security status in the INCA3 population $(n=1,774)$. * Significantly different from the reference ("Financially comfortable" for perception of financial situation, "Food sufficiency" for food insufficiency status, "Food security" for food security status) assessed by Dwass-Steel-Critchlow-Fligner (DSCF) test for pairwise multiple comparisons (significance was set at $\mathrm{P}<0.05$ ). 
Supplementary Material

Supplemental Method 1. Selection of nutrients and reference values to calculate the SecDiet score.

\section{Nutrients included:}

Vitamin A: Vitamin A is essential to ensure normal vision, growth and development. The main outcome related to vitamin A deficiency is xerophtalmia, which in the most extreme case can lead to irreversible blindness. IOM and EFSA have set their recommendations based on the intake necessary to ensure adequate stores ${ }^{(1-3)}$. Only the WHO has defined a minimum daily intake necessary to prevent xerophtalmia, in the absence of clinical or subclinical infection, without ensuring liver storage. This mean requirement has been estimated as $300 \mu \mathrm{g} R \mathrm{E} /$ day for men and $270 \mu \mathrm{g} /$ day for women ${ }^{(4)}$. These reference values were used as the deficiency threshold (DT) for vitamin $\mathrm{A}$, with a CV of $15 \%$.

Thiamin: Thiamin is an essential vitamin because of its role as a coenzyme in the metabolism of carbohydrates and branched-chain amino acids. Thiamin deficiency manifests itself in the form of beriberi disease or as Wernicke-Korsakoff syndrome. Reference values are mainly based on erythrocyte transketolase activity, which is used as a marker of thiamin status ${ }^{(1-3,5)}$. However, these reference values do not involve the onset of deficiency symptoms, so we defined an estimated deficiency threshold (eDT). This eDT was calculated as the intake covering the requirements of $2.5 \%$ of the population and is therefore estimated as $e D T=E A R(1-2 C V)=$ $R D A \frac{1-2 C V}{1+2 C V}$. The EFSA has set the EAR at $0.3 \mathrm{mg} / 1000 \mathrm{kcal} / \mathrm{day}$ and the RDA at $0.4 \mathrm{mg} / 1000 \mathrm{kcal} / \mathrm{day}$ with a CV of $20 \%{ }^{(1)}$. The eDT is therefore set at $0.18 \mathrm{mg} / 1000 \mathrm{kcal} / \mathrm{day}$. This threshold is quite consistent with studies that observed clinical signs of deficiency at intakes below $0.2 \mathrm{mg} / 1000 \mathrm{kcal}$, as reported by the $\mathrm{NCM}^{(5)}$.

Riboflavin: Riboflavin is a precursor of coenzymes that acts in numerous oxidation-reduction reactions in metabolic pathways and energy production. The clinical signs of riboflavin deficiency, ariboflavinosis, are nonspecific, and can take different forms such as a sore throat, cheilosis, angular stomatitis, etc. An adequate riboflavin intake has been determined using different indicators such as urinary riboflavin excretion, erythrocyte glutathione reductase activity coefficient or plasma riboflavin ${ }^{(2-5)}$. The EFSA used the inflection point of the urinary riboflavin excretion curve, which is a sign of body saturation, and set the EAR at $1.3 \mathrm{mg} / \mathrm{day}$ and the RDA at 1.6 $\mathrm{mg} /$ day with a CV of $10 \%{ }^{(1)}$. In the same way as for thiamin, reference values were not set at the onset of clinical signs of deficiency and an eDT was calculated and set at $1.0 \mathrm{mg} /$ day using EFSA reference values.

Niacin: Niacin is a precursor of the coenzymes involved in the metabolism of glucose, amino acids and fatty acids. Pellagra is the disease that appears in case of niacin deficiency. Niacin requirements are estimated using the urinary excretion of niacin metabolites and are expressed as niacin equivalent to take account of the conversion of tryptophan into niacin ${ }^{(2,3,5)}$. The EFSA based its reference values using depletion-repletion studies and set the EAR at $1.3 \mathrm{mg} \mathrm{NE} / \mathrm{MJ}$ 
(5.5 mg NE/1000kcal), based on the rationale that this intake is sufficient to prevent depletion and maintain niacin body stores. Assuming a CV of 10\%, the RDA was set at $1.6 \mathrm{mg} \mathrm{NE} / \mathrm{MJ}$ (6.6 mg $\mathrm{NE} / 1000 \mathrm{kcal})$. The EFSA also noted that there were no signs of niacin deficiency with intakes of at least $1 \mathrm{mg} / \mathrm{NE} / \mathrm{MJ}$ (4.4 mg NE/1000kcal) for a minimal daily energy intake of $8.4 \mathrm{MJ} /$ day $(2000 \mathrm{kcal} / \mathrm{day})^{(1)}$. Since the reference values were not based on the appearance of clinical signs of deficiency, an eDT was estimated, based on the EFSA reference values, and set at 1.0 $\mathrm{mg} / \mathrm{NE} / \mathrm{MJ}$ (4.35 mg/1000kcal), which is in line with the minimum intake indicated by EFSA and $\mathrm{NCM}^{(1,5)}$.

Folate: Folate acts as a coenzyme in the metabolism of nucleic and amino acids and is also fundamental for the normal functioning of the methionine cycle. The main clinical sign of folate deficiency in adults is megaloblastic anaemia. In pregnant women, folate intakes need to be increased to reduce risk of neural tube defects. The requirements for folate are based on the minimum amounts needed to maintain adequate levels of biomarkers such as serum or erythrocyte folates or plasma homocysteine ${ }^{(1,2,4)}$. Since the reference values were not based on the appearance of clinical signs of deficiency, an eDT was estimated based on the EFSA reference values. The EFSA has set an EAR of $250 \mu \mathrm{g} /$ day and a RDA of $330 \mu \mathrm{g} /$ day with a CV of $15 \%$, based on a depletion-repletion study ${ }^{(1)}$. The eDT was therefore set at $175 \mu \mathrm{g} / \mathrm{day}$.

Vitamin B12: Vitamin B12 plays an essential role in normal blood formation and neurological function. It acts as a coenzyme in the reaction that converts homocysteine to methionine and is also implicated in the metabolism of fatty acids and amino acids. The earliest symptom of vitamin B12 deficiency is similar to that of folate deficiency and takes the form of megaloblastic anaemia, but additional neurological dysfunction may eventually occur. The requirements for vitamin B12 are based on evaluating several biomarkers of vitamin B12 status ${ }^{(1-3)}$. The NNR determined that the lowest dietary intake needed to prevent anaemia is $1 \mu \mathrm{g} / \mathrm{day}^{(5)}$ and this value was selected as the threshold for the calculation of the SecDiet, with a CV of $15 \%$.

Vitamin C: Vitamin C acts as an enzyme cofactor and antioxidant. The clinical form of vitamin C deficiency is scurvy and occurs with a body pool lower than $300 \mathrm{mg}$ and a plasma ascorbate concentration lower than $11 \mu \mathrm{mol} / \mathrm{L}$. Scurvy can be prevented by an intake of $10 \mathrm{mg} /$ day of vitamin $\mathrm{C}^{(1,2,4)}$. This value was selected as the threshold for the calculation of the SecDiet with a CV of $10 \%$ (CV assumed by the EFSA ${ }^{(1)}$ ).

lodine: lodine is an essential component for the synthesis of thyroid hormones which are crucial for numerous physiological functions (growth, development of neurological and cognitive functions, protein synthesis, etc.). The consequence of iodine deficiency is impaired thyroid function that may lead to thyroid hypertrophy resulting in goitre, mental retardation or cretinism. lodine requirements are mainly based on thyroid iodine accumulation and turnover ${ }^{(1-3)}$. The EFSA has defined an Adequate Intake based on the prevalence of goitre. A European epidemiological study found that the lowest prevalence of goitre was observed with a urinary iodine concentration above $100 \mu \mathrm{g} / \mathrm{L}$, which corresponds to an iodine intake at around $150 \mu \mathrm{g} / \mathrm{day}$. An Adequate Intake of $150 \mu \mathrm{g} /$ day was thus defined for adults ${ }^{(1)}$. The Adequate Intake was taken as the deficiency 
threshold, with a CV of $20 \%$. However, it appears that this threshold overestimated the risk of iodine deficiency so, using the national prevalence of goitre (which is approximately $10 \%$ in France ${ }^{(6)}$ ), we readjusted the estimation of the risk of deficiency (by dividing the deficiency threshold by an adequate factor of 1.5) in order to obtain a probability of adequacy of 0.9 in the French national representative survey INCA3. The recalibrated DT was therefore set at $100 \mu \mathrm{g} / \mathrm{day}$ with a CV of $20 \%$.

Selenium: Selenium, via selenoproteins, plays a role, among others, in the metabolism of thyroid hormones and in the defences against oxidative stress. Selenium requirements are defined as the intake needed to maximize the activity of plasma selenoprotein glutathione peroxidase ${ }^{(2,3)}$. Selenium deficiency leads to Keshan disease, which was first observed in Chinese regions where soil selenium concentrations are low. Epidemiological studies were used to establish a population basal requirement for selenium and concluded that Keshan disease was not present in regions where the mean intake of selenium for adults was higher than $19.1 \mu \mathrm{g} / \mathrm{day}$ for males and 13.3 $\mu \mathrm{g} /$ day for females. These thresholds were adapted to use a standard reference body weight of $65 \mathrm{~kg}$ for men and $55 \mathrm{~kg}$ for women. The population minimum intake of selenium defined by the FAO is therefore $21 \mu \mathrm{g} /$ day for males and $16 \mu \mathrm{g} /$ day for females ${ }^{(4,7)}$, and this was taken as the reference for the SecDiet with a CV of 15\%.

Iron: Most of the body's iron reserves are found in hemoglobin and muscle myoglobin and contribute to oxygen transport. Iron deficiency causes anaemia, which is the most common nutritional deficiency worldwide, and corresponds to low haemoglobin concentrations. Iron deficiency can also lead to depleted stores when serum ferritin concentrations are low. Iron intake requirements are based on the modelling of obligatory losses while taking account of iron absorption $^{(1,2)}$. Although the requirements are not based on iron deficiency, we considered that those based on obligatory losses were adequate to define the deficiency threshold. We therefore considered the Anses recommendations that are based on the modeling of obligatory losses but applied to bioavailable iron. For men and non-menstruating women, an EAR of $6 \mathrm{mg} / \mathrm{d}$, RDA of $11 \mathrm{mg} / \mathrm{d}$ and CV of $40 \%$ defined by Anses were therefore used for iron ${ }^{(3)}$. Assuming iron absorption of $16 \%$, the EAR and RDA correspond respectively to $0.95 \mathrm{mg} / \mathrm{day}$ and $1.74 \mathrm{mg} / \mathrm{day}$ of bioavailable iron. The deficiency threshold was therefore set at $1.74 \mathrm{mg} / \mathrm{d}$ of bioavailable iron, with a CV of $40 \%$. For menstruating women, the distribution of their requirements is not normal and was modelled using a lognormal function by adding basal iron losses (normally distributed) to menstrual losses (exponentially distributed, $\lambda=\ln (2) / 0.28)$ with a Monte-Carlo simulation on 1000 individuals in the same way as the calculation of the PANDiet ${ }^{(8)}$. Since the combination of basal and menstrual losses followed a lognormal distribution, it was considered that the logarithm of physiological requirements followed a normal distribution $(\mu=0.18, \sigma=0.34)$. As for iodine, the threshold used overestimated the risk of iron deficiency, so based on the prevalence of anaemia in the French population ( $2 \%$ among men and $5.1 \%$ among women ${ }^{(9)}$ ) we readjusted it by dividing by a factor of 2.5 for men and non-menstruating women and 2.8 for menstruating women in order to obtain a probability of adequacy of 0.98 for men and 0.95 for women in the French national representative survey INCA3. The corrected DT was set at $0.70 \mathrm{mg} /$ day with a CV of $40 \%$ for men and non-menstruating women. For menstruating women, the DT was set at $0.83 \mathrm{mg} / \mathrm{day}$. 
Bioavailable iron was estimated using a mathematical model. Nonhaeme iron absorption is dependent on individual concentration of serum ferritin and on dietary factors such as vitamin $\mathrm{C}$, meat, fish and poultry, tea, phytate and calcium intakes. Haeme iron absorption is only dependent on serum ferritin levels. The following equation was used to calculate nonhaeme iron absorption $^{(10)}$ :

$$
\begin{aligned}
& \text { Ln Absorption (\%) } \\
& \qquad \begin{aligned}
= & 6.294-0.709 \ln (\mathrm{SF})+0.119 \ln (\mathrm{C})+0.006 \ln (\mathrm{MFP}+0.1) \\
& -0.055 \ln (T+0.1)-0.247 \ln (P)-0.137 \ln (\mathrm{Ca})-0.083 \ln (N H)
\end{aligned}
\end{aligned}
$$

For haeme iron absorption, the following equation was used ${ }^{(11)}$ :

$$
\text { Log Absorption }(\%)=1.9897-0.3092 \times \log (\mathrm{SF})
$$

where SF is serum ferritin ( $\mathrm{mg} / \mathrm{L}), \mathrm{C}$ is vitamin C $(\mathrm{mg}), \mathrm{MFP}$ is meat, fish, and poultry $(\mathrm{g}), \mathrm{T}$ is tea (number of cups), $\mathrm{P}$ is phytate (mg), $\mathrm{Ca}$ is calcium (mg), and $\mathrm{NH}$ is nonhaeme iron (mg).

Because no data were available on the serum ferritin status of individuals, the serum ferritin level was set at $15 \mathrm{mg} / \mathrm{L}$ corresponding to the cut-off value for low ferritin stores. However, this hypothesis overestimates the absorption, since iron absorption is maximal at low ferritin stores.

Zinc: Zinc is essential for growth and development and has a catalytic role in various enzymatic processes. There are no specific clinical signs of deficiency in adults but skin lesions, diarrhoea, alopecia, impaired immune system may appear. In children, growth retardation is the main clinical sign. A vegetarian diet may lead to low zinc status because of the high content in plant-based foods of phytates that reduce zinc absorption. There are no adequate biomarkers for zinc status from which to derive requirements. Zinc requirements were thus estimated using a factorial approach considering physiological requirements, by estimating total daily losses and zinc absorption $^{(1,2,4,12)}$. We estimated the deficiency threshold for bioavailable zinc from estimates of obligatory losses. For men, urinary and sweat losses, integumental losses and losses in semen are estimated respectively at $0.63 \mathrm{mg} / \mathrm{d}, 0.54 \mathrm{mg} / \mathrm{d}$ and $0.1 \mathrm{mg} / \mathrm{d}$. For women, urinary and sweat losses, integumental losses and menstrual losses are estimated respectively at $0.44 \mathrm{mg} / \mathrm{d}, 0.46$ $\mathrm{mg} / \mathrm{d}$ and $0.1 \mathrm{mg} / \mathrm{d}^{(5,13)}$. Losses from the intestine could not be precisely determined because they depend on the quantity of zinc absorbed, and this was estimated to be $0.3 \mathrm{mg} / \mathrm{d}$. It was therefore considered that total endogenous losses reached $1.6 \mathrm{mg} / \mathrm{d}$ for men and $1.3 \mathrm{mg} / \mathrm{d}$ for women and these two values were retained to define the deficiency threshold, with a CV of $15 \%$.

The following mathematical model was used to calculate bioavailable zinc from dietary zinc and phytate intakes $^{(14)}$ :

$$
\begin{aligned}
T A Z=0.5 \times\{ & 0.13+T D Z+0.10\left(1+\frac{T D P}{1.2}\right) \\
& \left.-\sqrt{\left(0.13+T D Z+0.10\left(1+\frac{T D P}{1.2}\right)\right)^{2}-4 \times 0.13 \times T D Z}\right\}
\end{aligned}
$$

TAZ: total absorbed zinc (mmol), TDZ: total dietary zinc (mmol) and TDP: total dietary phytate (mmol). 
Calcium: Calcium is an essential and structural component of the skeleton and more than 99 percent of total body calcium is present in the bones and teeth. When intakes are inadequate, calcium is resorbed from the skeleton in order to maintain normal circulating concentrations, making it difficult to estimate calcium nutritional status and requirements. On the long term, this resorption reduces bone mineral density and chronic calcium deficiency can lead to osteopenia and osteoporosis and an increased risk of fractures. Calcium requirements are difficult to estimate because of calcium homeostasis and the absence of short-term clinical manifestations of calcium deficiency. Health agencies have therefore based their requirements on balanced studies ${ }^{(1,2,12)}$. Over the long term, it is assumed that intake should not be lower than $500 \mathrm{mg} / \mathrm{d}$ for adults to maintain a consistent balance ${ }^{(5,12)}$ and several meta-analyses have concluded that there was no significant association between calcium intake and fracture risk with a calcium intake higher than $500 \mathrm{mg} / \mathrm{d}^{(15-17)}$. This value of $500 \mathrm{mg} / \mathrm{d}$ was retained for our study to define the deficiency threshold, with a CV of $15 \%$.

\section{Nutrients not included:}

Pantothenic acid: Pantothenic acid is widely found in foods and isolated pantothenic acid deficiency has almost never been observed, except under experimental conditions ${ }^{(2,4,12)}$.

Vitamin B6: Vitamin B6 is frequently found in foods and vitamin B6 deficiency is extremely rare; it has only been observed during depletion with very low level of vitamin B6 or in association with other B-vitamin deficiencies ${ }^{(2,4,12)}$.

Vitamin B8: No deficiency has been observed in healthy humans under normal conditions but only in individuals receiving total parenteral nutrition without biotin or those consuming raw egg whites over a long period ${ }^{(2,4,12)}$.

Vitamin D: Vitamin D deficiency can occur in the form of rickets in children and osteomalacia in adults. Despite its fundamental role in human metabolism, vitamin D was not considered for the calculation of the SecDiet because it can be synthesized endogenously in adequate quantities through exposure to the sun and the requirements are generally determined based on low sun exposure $^{(1,3,12)}$. It would therefore be inaccurate to evaluate the risk of vitamin $\mathrm{D}$ deficiency by only considering food intake, so it was not included in the SecDiet.

Vitamin E: Vitamin E deficiency is very rare and has only been observed in individuals with medical conditions that alter its absorption or metabolism. Vitamin E deficiency due to a low intake has never been described in healthy individuals ${ }^{(2,4,5)}$.

Vitamin K: Vitamin K plays a role in blood coagulation. Vitamin $\mathrm{K}$ deficiency can be found in infants that are exclusively breast-fed and can cause bleeding, but has not been observed in adults, except when a pathology interferes with absorption of the vitamin ${ }^{(2,4,12)}$.

Copper: Copper deficiency is rare in humans and has only been observed in patients receiving prolonged total parenteral nutrition, in the case of genetic mutations affecting copper metabolism $^{(1,2)}$ or in patients who have undergone bariatric surgery ${ }^{(18)}$.

Manganese: Clinical signs of manganese deficiency have not been clearly described in humans and it has only been observed in few cases of patients receiving parenteral nutrition ${ }^{(1,2,12)}$. 
Phosphorus: Phosphorus is widespread in foods. Phosphorus deficiency is unlikely to be caused by an inadequate phosphorus intake, but only in the event of metabolic disorders or in patients receiving parenteral nutrition ${ }^{(1,2,12)}$.

Potassium: Potassium is found in all foods and potassium deficiency is not caused by an inadequate potassium intake but can be caused by increased potassium losses (diarrhea, vomiting, abuse of laxatives and diuretics) $)^{(1,12)}$.

Sodium: Sodium deficiency is rare in healthy adults. Nowadays there are more concerns about excess intakes rather than insufficient intakes ${ }^{(2,12,19)}$.

Magnesium: Magnesium deficiency may be observed in some diseases or with chronic alcoholism, or in the case of a low magnesium intake combined with important losses (prolonged diarrhea, excessive urinary magnesium losses) but otherwise overt deficiency is not common in healthy adults $^{(2,4,12)}$.

Chromium: There is insufficient scientific evidence of how essential chromium is in humans; chromium deficiency has only been observed in patients receiving total parenteral nutrition without chromium supplementation ${ }^{(1,2)}$.

Fluoride: Fluoride plays an important role in the prevention of caries and an insufficient fluoride intake increases the risk of dental caries. However, fluoride is not considered as an essential nutrient ${ }^{(1,2)}$.

Molybdenum: Molybdenum deficiency has not been observed in healthy humans ${ }^{(1,2)}$. 
Supplemental Method 2. The PANDiet score is expressed as the average of an adequacy subscore (AS - accounting for 27 nutrients) and a moderation subscore (MS - accounting for six nutrients, plus 12 potential penalty values). DHA and EPA+DHA are weighted by a factor of $1 / 2$ as DHA is present twice. Niacin equivalents were calculated as the sum of dietary niacin and 1/60 dietary tryptophan. The upper reference value for sugars excludes lactose. The tolerable upper intake limit for vitamin A concerns retinol only. Version 3.1 of the PANDiet is based on the dietary reference intake from the 2016 Anses opinion $^{(3)}$ and the overall construction of the score has been described elsewhere ${ }^{(20,21)}$.

\begin{tabular}{|c|c|c|c|c|c|c|c|}
\hline \multicolumn{8}{|c|}{ PANDiet score } \\
\hline \multicolumn{8}{|c|}{ Average of Adequacy and Moderation subscores } \\
\hline \multicolumn{4}{|c|}{ Adequacy subscore } & \multicolumn{4}{|c|}{ Moderation subscore } \\
\hline Nutrient & Reference value (/day) & Variability & Source & Nutrient & $\begin{array}{c}\text { Reference } \\
\text { value (Iday) }\end{array}$ & Variability & Source \\
\hline Protein & 0.66 or $0.8 \mathrm{~g} / \mathrm{kg} \mathrm{bw}$ & $12.5 \%$ & $(22,23)$ & Protein & $2.2 \mathrm{~g} / \mathrm{kg} \mathrm{bw}$ & $12.5 \%$ & (3) \\
\hline LA & $3.08 \%$ EIEA & $15 \%$ & (24) & Total fat & $44 \%$ EIEA & $5 \%$ & (3) \\
\hline ALA & $0.769 \%$ EIEA & $15 \%$ & (24) & SFA & $12 \%$ EIEA & $15 \%$ & (3) \\
\hline DHA & $0.192 \mathrm{~g}$ & $15 \%$ & (24) & Carbohydrates & $60.5 \%$ EIEA & $5 \%$ & (3) \\
\hline EPA + DHA & $0.385 \mathrm{~g}$ & $15 \%$ & (24) & Sugars & $100 \mathrm{~g}$ & $15 \%$ & (3) \\
\hline Fibre & $23 \mathrm{~g}$ & $15 \%$ & (3) & Sodium & $\begin{array}{c}3482 \text { or } 2618 \\
\mathrm{mg}\end{array}$ & $40 \%$ & (3) \\
\hline Vitamin A & 570 or $490 \mu g$ & $15 \%$ & (3) & \multirow{2}{*}{\multicolumn{2}{|c|}{ Tolerable Upper Intake Limits }} & & \\
\hline Thiamin & $0.3 \mathrm{mg} / 1000 \mathrm{kcal}$ & $20 \%$ & (1) & & & \multicolumn{2}{|c|}{ Source } \\
\hline Riboflavin & $1.3 \mathrm{mg}$ & $10 \%$ & (1) & Vitamin A & $3000 \mu \mathrm{g}$ & \multicolumn{2}{|c|}{ (3) } \\
\hline Niacin & $5.44 \mathrm{mg} \mathrm{NE} / 1000 \mathrm{kcal}$ & $10 \%$ & (3) & Niacin & $900 \mathrm{mg}$ & \multicolumn{2}{|c|}{ (3) } \\
\hline $\begin{array}{l}\text { Pantothenic } \\
\text { acid }\end{array}$ & 3.62 or $2.94 \mathrm{mg}$ & $30 \%$ & (3) & Vitamin B6 & $25 \mathrm{mg}$ & \multicolumn{2}{|c|}{ (3) } \\
\hline Vitamin B-6 & 1.5 or $1.3 \mathrm{mg}$ & $10 \%$ & (25) & Folate & $1170 \mu \mathrm{g}$ & \multicolumn{2}{|c|}{ (3) } \\
\hline Folate & $250 \mu \mathrm{g}$ & $15 \%$ & (3) & Vitamin D & $100 \mu \mathrm{g}$ & \multicolumn{2}{|c|}{ (3) } \\
\hline Vitamin B-12 & $3.33 \mu \mathrm{g}$ & $10 \%$ & (3) & Vitamin E & $300 \mathrm{mg}$ & \multicolumn{2}{|c|}{ (3) } \\
\hline Vitamin C & $90 \mathrm{mg}$ & $10 \%$ & (3) & Calcium & $2500 \mathrm{mg}$ & \multicolumn{2}{|c|}{ (3) } \\
\hline Vitamin D & $10 \mu \mathrm{g}$ & $25 \%$ & (3) & Copper & $10 \mathrm{mg}$ & \multicolumn{2}{|c|}{ (3) } \\
\hline Vitamin E & 5.8 or $5.5 \mathrm{mg}$ & $40 \%$ & (3) & lodine & $600 \mu \mathrm{g}$ & \multicolumn{2}{|c|}{ (3) } \\
\hline Calcium & $\begin{array}{c}860 \text { (< }=24 \text { y.o }) \text { or } 750 \\
(>24 \text { y.o. })\end{array}$ & $15 \%$ or $13 \%$ & (3) & $\begin{array}{l}\text { Dissociable } \\
\text { magnesium }\end{array}$ & $250 \mathrm{mg}$ & \multicolumn{2}{|c|}{ (3) } \\
\hline Copper & 1.0 or $0.8 \mathrm{mg}$ & $15 \%$ & (3) & Selenium & $300 \mu \mathrm{g}$ & \multicolumn{2}{|c|}{ (3) } \\
\hline lodine & $107 \mu \mathrm{g}$ & $20 \%$ & (3) & Zinc & $25 \mathrm{mg}$ & \multicolumn{2}{|c|}{ (3) } \\
\hline $\begin{array}{l}\text { Bioavailable } \\
\text { iron }\end{array}$ & \multicolumn{2}{|c|}{ See Supplemental Method 1} & (3) & & & & \\
\hline Magnesium & $5 \mathrm{mg} / \mathrm{kg} \mathrm{bw}$ & $15 \%$ & (3) & & & & \\
\hline Manganese & 1.56 or $1.39 \mathrm{mg}$ & $40 \%$ & (3) & & & & \\
\hline Phosphorus & $\begin{array}{l}\text { Calcium (mmol) / } 1.65 \\
\text { c.f. phosphorus section in } \\
\text { de Gavelle et al. }{ }^{(8)}\end{array}$ & $\begin{array}{l}7.5 \%+C V \\
\text { Calcium } \\
(\mathrm{mg})\end{array}$ & (1) & & & & \\
\hline Potassium & $2692 \mathrm{mg}$ & $15 \%$ & (1) & & & & \\
\hline Selenium & $54 \mu \mathrm{g}$ & $15 \%$ & (3) & & & & \\
\hline $\begin{array}{l}\text { Bioavailable } \\
\text { zinc }\end{array}$ & $0.642+0.038$ b.w. & $10 \%$ & (3) & & & & \\
\hline
\end{tabular}

bw, body weight; LA, linoleic acid; EIEA, energy intake excluding alcohol; ALA, alpha-linolenic acid; DHA,

docosahexaenoic acid; EPA, eicosapentaenoic acid; NE, niacin equivalent; CV, coefficient of variation; SFA, saturated fatty acids. 
Supplemental Table 1: Spearman rank correlation coefficients $(r)$ between the SecDiet score and its probabilities of adequacy, the PANDiet score and total energy intake in the French adult population, INCA3, n=1,774.

\begin{tabular}{|c|c|c|c|c|c|c|c|c|c|c|c|c|c|}
\hline & $\begin{array}{l}\text { SecDiet } \\
\text { score }\end{array}$ & Calcium & Zinc & Iron & Selenium & lodine & Vitamin C & Vitamin B12 & Folate & Niacin & Riboflavin & Thiamin & Vitamin A \\
\hline \multicolumn{14}{|c|}{ Probabilities of adequacy } \\
\hline Vitamin A & $\begin{array}{c}0.68 \dagger \\
(0.65,0.70) \text { ** }\end{array}$ & $\begin{array}{c}0.43 \\
(0.39,0.47) \text { ** }\end{array}$ & $\begin{array}{c}0.31 \\
(0.27,0.35) \text { ** }\end{array}$ & $\begin{array}{c}0.21 \\
(0.17,0.26) * *\end{array}$ & $\begin{array}{c}0.26 \\
(0.21,0.30) \text { * }\end{array}$ & $\begin{array}{c}0.40 \\
(0.36,0.44) \text { * }\end{array}$ & $\begin{array}{c}0.24 \\
(0.19,0.28) * * \\
\end{array}$ & $\begin{array}{c}0.27 \\
(0.23,0.32)\end{array}$ & $\begin{array}{c}0.48 \\
(0.44,0.51) * *\end{array}$ & $\begin{array}{c}0.07 \\
(0.03,0.12) \text { * }\end{array}$ & $\begin{array}{c}0.44 \\
(0.40,0.48) * *\end{array}$ & $\begin{array}{c}0.10 \\
(0.05,0.14) * *\end{array}$ & 1 \\
\hline Thiamin & $\begin{array}{c}0.17 \\
(0.13,0.22) * *\end{array}$ & $\begin{array}{c}0.13 \\
(0.08,0.17) \text { ** }\end{array}$ & $\begin{array}{c}0.08 \\
(0.03,0.12) * \\
\end{array}$ & $\begin{array}{c}0.11 \\
(0.06,0.15) * *\end{array}$ & $\begin{array}{c}0.09 \\
(0.04,0.14) \text { * }\end{array}$ & $\begin{array}{c}0.15 \\
(0.11,0.20) \text { * }\end{array}$ & $\begin{array}{c}0.15 \\
(0.10,0.19) * *\end{array}$ & $\begin{array}{c}0.06 \\
(0.01,0.11) \text { * }\end{array}$ & $\begin{array}{c}0.16 \\
(0.12,0.21) \text { * }\end{array}$ & $\begin{array}{c}0.18 \\
(0.13,0.23) * *\end{array}$ & $\begin{array}{c}0.16 \\
(0.12,0.21) * *\end{array}$ & 1 & \\
\hline Riboflavin & $\begin{array}{c}0.74 \\
(0.71,0.76) * * \\
\end{array}$ & $\begin{array}{c}0.64 \\
(0.61,0.66)\end{array}$ & $\begin{array}{c}0.52 \\
(0.48,0.55) \text { * } \\
\end{array}$ & $\begin{array}{c}0.42 \\
(0.38,0.45) * *\end{array}$ & $\begin{array}{c}0.38 \\
(0.34,0.42) \text { * }\end{array}$ & $\begin{array}{c}0.61 \\
(0.58,0.64) * *\end{array}$ & $\begin{array}{c}0.29 \\
(0.25,0.33) * *\end{array}$ & $\begin{array}{c}0.46 \\
(0.42,0.49) * *\end{array}$ & $\begin{array}{c}0.56 \\
(0.53,0.59) * *\end{array}$ & $\begin{array}{c}0.17 \\
(0.12,0.21) \star *\end{array}$ & 1 & & \\
\hline Niacin & $\begin{array}{c}0.20 \\
(0.16,0.25) \text { ** }\end{array}$ & $\begin{array}{c}0.14 \\
(0.09,0.18) \text { ** }\end{array}$ & $\begin{array}{c}0.14 \\
(0.09,0.19)\end{array}$ & $\begin{array}{c}0.20 \\
(0.15,0.24) * *\end{array}$ & $\begin{array}{c}0.09 \\
(0.05,0.14) \text { * }\end{array}$ & $\begin{array}{c}0.17 \\
(0.13,0.22) \text { * }\end{array}$ & $\begin{array}{c}0.11 \\
(0.07,0.16) * *\end{array}$ & $\begin{array}{c}0.12 \\
(0.07,0.16) \text { * }\end{array}$ & $\begin{array}{c}0.15 \\
(0.10,0.19) * *\end{array}$ & 1 & & & \\
\hline Folate & $\begin{array}{c}0.70 \\
(0.68,0.73) \star * \\
\end{array}$ & $\begin{array}{c}0.49 \\
(0.45,0.52)\end{array}$ & $\begin{array}{c}0.37 \\
(0.33,0.41) * \\
\end{array}$ & $\begin{array}{c}0.40 \\
(0.36,0.44) * *\end{array}$ & $\begin{array}{c}0.37 \\
(0.32,0.40) *\end{array}$ & $\begin{array}{c}0.53 \\
(0.49,0.56) * \\
\end{array}$ & $\begin{array}{c}0.43 \\
(0.39,0.46) *\end{array}$ & $\begin{array}{c}0.31 \\
(0.27,0.35) *\end{array}$ & 1 & & & & \\
\hline Vitamin B12 & $\begin{array}{c}0.51 \\
(0.48,0.55) * *\end{array}$ & $\begin{array}{c}0.38 \\
(0.34,0.42)\end{array}$ & $\begin{array}{c}0.48 \\
(0.44,0.51) * *\end{array}$ & $\begin{array}{c}0.33 \\
(0.28,0.37)^{*}\end{array}$ & $\begin{array}{c}0.28 \\
(0.24,0.32) \text { * }\end{array}$ & $\begin{array}{c}0.36 \\
(0.32,0.40) \text { * }\end{array}$ & $\begin{array}{c}0.14 \\
(0.09,0.18) * *\end{array}$ & 1 & & & & & \\
\hline Vitamin C & $\begin{array}{c}0.42 \\
(0.38,0.46)\end{array}$ & $\begin{array}{c}0.24 \\
(0.20,0.28) \text { ** }\end{array}$ & $\begin{array}{c}0.21 \\
(0.17,0.25) \text { ** }\end{array}$ & $\begin{array}{c}0.30 \\
(0.26,0.34) * *\end{array}$ & $\begin{array}{c}0.24 \\
(0.19,0.28) * *\end{array}$ & $\begin{array}{c}0.25 \\
(0.21,0.29)\end{array}$ & 1 & & & & & & \\
\hline lodine & $\begin{array}{c}0.78 \\
(0.76,0.79) \text { * }\end{array}$ & $\begin{array}{c}0.58 \\
(0.55,0.61) \text { ** }\end{array}$ & $\begin{array}{c}0.40 \\
(0.36,0.44) \text { ** }\end{array}$ & $\begin{array}{c}0.38 \\
(0.34,0.42) * *\end{array}$ & $\begin{array}{c}0.38 \\
(0.34,0.42) \text { * }\end{array}$ & 1 & & & & & & & \\
\hline Selenium & $\begin{array}{c}0.41 \\
(0.37,0.45) * *\end{array}$ & $\begin{array}{c}0.35 \\
(0.31,0.39) \text { ** }\end{array}$ & $\begin{array}{c}0.27 \\
(0.22,0.31) \text { ** }\end{array}$ & $\begin{array}{c}0.21 \\
(0.16,0.25) * *\end{array}$ & 1 & & & & & & & & \\
\hline Iron & $\begin{array}{c}0.51 \\
(0.48,0.55) * *\end{array}$ & $\begin{array}{c}0.30 \\
(0.26,0.34)^{\star *}\end{array}$ & $\begin{array}{c}0.51 \\
(0.47,0.54) * *\end{array}$ & 1 & & & & & & & & & \\
\hline Zinc & $\begin{array}{c}0.54 \\
(0.50,0.57)^{* *}\end{array}$ & $\begin{array}{c}0.49 \\
(0.45,0.52) \text { ** } \\
\end{array}$ & 1 & & & & & & & & & & \\
\hline Calcium & $\begin{array}{c}0.70 \\
(0.68,0.73) \text { ** }\end{array}$ & 1 & & & & & & & & & & & \\
\hline $\begin{array}{l}\text { Total energy } \\
\text { intake }\end{array}$ & $\begin{array}{c}0.44 \\
(0.40,0.47) \text { ** }\end{array}$ & & & & & & & & & & & & \\
\hline $\begin{array}{l}\text { PANDiet } \\
\text { score }\end{array}$ & $\begin{array}{c}0.50 \\
(0.46,0.53) \text { ** }\end{array}$ & & & & & & & & & & & & \\
\hline
\end{tabular}


Supplemental Table 2: The SecDiet score and its probabilities of adequacy according to monthly income per household unit in the French adult population from the INCA3 survey, $\mathrm{n}=1,774$

\begin{tabular}{|c|c|c|c|c|c|c|c|c|c|c|c|}
\hline & \multicolumn{11}{|c|}{ Monthly income per household unit $(€)$} \\
\hline & \multicolumn{2}{|c|}{$\begin{array}{l}>1850 € \\
(n=607)\end{array}$} & \multicolumn{2}{|c|}{$\begin{array}{c}1340-1850 € \\
(n=402)\end{array}$} & \multicolumn{2}{|c|}{$\begin{array}{c}900-1340 € \\
(n=355)\end{array}$} & \multicolumn{2}{|c|}{$\begin{array}{l}<900 € \\
(n=281)\end{array}$} & \multicolumn{2}{|c|}{$\begin{array}{c}\text { Not available } \\
(n=129)\end{array}$} & \multirow[b]{2}{*}{$P^{\dagger}$} \\
\hline & Mean & SD & Mean & SD & Mean & SD & Mean & SD & Mean & $\mathrm{SD}$ & \\
\hline SecDiet (0-1) & 0.94 & 0.07 & 0.93 & 0.08 & 0.92 & 0.10 & 0.91 & 0.11 & 0.93 & 0.07 & \\
\hline $\begin{array}{l}\text { Median } \\
\text { Q1-Q3 }\end{array}$ & \multicolumn{2}{|c|}{$\begin{array}{c}0.97 \\
0.93-0.99 \\
\end{array}$} & \multicolumn{2}{|c|}{$\begin{array}{c}0.96 \\
0.91-0.99 \\
\end{array}$} & \multicolumn{2}{|c|}{$\begin{array}{c}0.96^{*} \\
0.89-0.99 \\
\end{array}$} & \multicolumn{2}{|c|}{$\begin{array}{c}0.95^{\star} \\
0.87-0.99 \\
\end{array}$} & \multicolumn{2}{|c|}{$\begin{array}{c}0.96^{*} \\
0.89-0.99 \\
\end{array}$} & 0.002 \\
\hline PANDiet (0-100) & 64.96 & 4.83 & 64.60 & 5.85 & 64.08 & 6.00 & 64.05 & 7.33 & 63.63 & 5.41 & \\
\hline $\begin{array}{l}\text { Median } \\
\text { Q1-Q3 }\end{array}$ & \multicolumn{2}{|c|}{$\begin{array}{c}65.09 \\
61.70-68.17 \\
\end{array}$} & \multicolumn{2}{|c|}{$\begin{array}{c}64.45 \\
60.95-68.71 \\
\end{array}$} & \multicolumn{2}{|c|}{$\begin{array}{c}64.81 \\
59.96-68.27 \\
\end{array}$} & \multicolumn{2}{|c|}{$\begin{array}{c}64.14 \\
59.60-68.72 \\
\end{array}$} & \multicolumn{2}{|c|}{$\begin{array}{c}63.90 \\
58.58-66.78 \\
\end{array}$} & 0.058 \\
\hline \multicolumn{12}{|c|}{ Probabilities of adequacy for SecDiet (0-1) } \\
\hline Vitamin A & 0.92 & 0.14 & 0.91 & 0.15 & 0.90 & 0.19 & 0.84 & 0.27 & 0.91 & 0.15 & - \\
\hline Thiamin & 1.00 & 0.01 & 1.00 & 0.01 & 1.00 & 0.01 & 1.00 & 0.01 & 1.00 & 0.00 & - \\
\hline Riboflavin & 0.96 & 0.10 & 0.95 & 0.12 & 0.93 & 0.16 & 0.93 & 0.14 & 0.94 & 0.08 & - \\
\hline Niacin & 1.00 & 0.01 & 1.00 & 0.01 & 1.00 & 0.00 & 1.00 & 0.02 & 1.00 & 0.00 & - \\
\hline Folate & 0.96 & 0.10 & 0.95 & 0.10 & 0.92 & 0.17 & 0.94 & 0.13 & 0.92 & 0.14 & - \\
\hline Vitamin B12 & 0.98 & 0.04 & 0.97 & 0.06 & 0.97 & 0.06 & 0.97 & 0.06 & 0.97 & 0.04 & - \\
\hline Vitamin C & 0.98 & 0.05 & 0.97 & 0.05 & 0.97 & 0.05 & 0.97 & 0.06 & 0.97 & 0.05 & - \\
\hline Iodine & 0.91 & 0.15 & 0.90 & 0.15 & 0.90 & 0.16 & 0.89 & 0.18 & 0.92 & 0.11 & - \\
\hline Selenium & 0.99 & 0.02 & 0.99 & 0.02 & 0.99 & 0.03 & 0.99 & 0.03 & 0.99 & 0.03 & - \\
\hline Iron & 0.97 & 0.05 & 0.96 & 0.08 & 0.96 & 0.07 & 0.96 & 0.08 & 0.97 & 0.04 & - \\
\hline Zinc & 0.99 & 0.04 & 0.99 & 0.06 & 0.98 & 0.05 & 0.98 & 0.06 & 0.99 & 0.04 & - \\
\hline Calcium & 0.96 & 0.09 & 0.95 & 0.12 & 0.94 & 0.15 & 0.9 & 0.21 & 0.92 & 0.13 & - \\
\hline
\end{tabular}


Supplemental Table 3: The SecDiet score and its probabilities of adequacy according to monthly income per household unit in the French adult population from the NutriNet-Santé study, $n=104,382$.

\begin{tabular}{|c|c|c|c|c|c|c|c|c|c|c|c|c|c|c|c|c|c|}
\hline & \multicolumn{17}{|c|}{ Monthly income per household unit (€) } \\
\hline & \multicolumn{2}{|c|}{$\begin{array}{l}>3700 € \\
(n=9938)\end{array}$} & \multicolumn{2}{|c|}{$\begin{array}{c}2700-3700 € \\
(n=14382)\end{array}$} & \multicolumn{2}{|c|}{$\begin{array}{c}2300-2700 € \\
(n=9129)\end{array}$} & \multicolumn{2}{|c|}{$\begin{array}{c}1800-2300 € \\
(n=14986)\end{array}$} & \multicolumn{2}{|c|}{$\begin{array}{c}1200-1800 € \\
(n=25632)\end{array}$} & \multicolumn{2}{|c|}{$\begin{array}{c}900-1200 € \\
(n=6740)\end{array}$} & \multicolumn{2}{|c|}{$\begin{array}{c}<900 € \\
(n=11277)\end{array}$} & \multicolumn{2}{|c|}{$\begin{array}{c}\text { Not available } \\
(n=12297)\end{array}$} & \multirow[b]{2}{*}{$P^{\dagger}$} \\
\hline & Mean & SD & Mean & $\mathrm{SD}$ & Mean & $\mathrm{SD}$ & Mean & SD & Mean & SD & Mean & SD & Mean & SD & Mean & SD & \\
\hline SecDiet (0-1) & 0.97 & 0.05 & 0.97 & 0.05 & 0.97 & 0.05 & 0.96 & 0.06 & 0.96 & 0.06 & 0.95 & 0.07 & 0.94 & 0.08 & 0.95 & 0.07 & \\
\hline $\begin{array}{l}\text { Median } \\
\text { Q1-Q3 } \\
\end{array}$ & \multicolumn{2}{|c|}{$\begin{array}{c}0.99 \\
0.97-1.00 \\
\end{array}$} & \multicolumn{2}{|c|}{$\begin{array}{c}0.99 \\
0.96-1.00\end{array}$} & \multicolumn{2}{|c|}{$\begin{array}{c}0.98^{\star} \\
0.96-1.00 \\
\end{array}$} & \multicolumn{2}{|c|}{$\begin{array}{c}0.98^{*} \\
0.96-1.00 \\
\end{array}$} & \multicolumn{2}{|c|}{$\begin{array}{c}0.98^{*} \\
0.95-0.99 \\
\end{array}$} & \multicolumn{2}{|c|}{$\begin{array}{c}0.98^{\star} \\
0.94-0.99 \\
\end{array}$} & \multicolumn{2}{|c|}{$\begin{array}{c}0.97^{*} \\
0.91-0.99\end{array}$} & \multicolumn{2}{|c|}{$\begin{array}{c}0.98^{\star} \\
0.94-0.99 \\
\end{array}$} & $<0.001$ \\
\hline PANDiet (0-100) & 62.50 & 6.96 & 61.99 & 7.00 & 61.52 & 7.03 & 61.26 & 7.24 & 60.31 & 7.14 & 59.47 & 7.14 & 59.31 & 7.55 & 60.94 & 7.49 & \\
\hline $\begin{array}{l}\text { Median } \\
\text { Q1-Q3 }\end{array}$ & \multicolumn{2}{|c|}{$\begin{array}{c}61.99 \\
57.54-67.02 \\
\end{array}$} & \multicolumn{2}{|c|}{$\begin{array}{c}61.36^{\star} \\
57.04-66.47 \\
\end{array}$} & \multicolumn{2}{|c|}{$\begin{array}{c}60.86^{*} \\
56.64-65.97 \\
\end{array}$} & \multicolumn{2}{|c|}{$\begin{array}{c}60.60^{\star} \\
56.25-65.83 \\
\end{array}$} & \multicolumn{2}{|c|}{$\begin{array}{c}59.73^{\star} \\
55.36-64.76 \\
\end{array}$} & \multicolumn{2}{|c|}{$\begin{array}{c}58.82^{\star} \\
54.41-63.83 \\
\end{array}$} & \multicolumn{2}{|c|}{$\begin{array}{c}58.64^{*} \\
53.99-63.99 \\
\end{array}$} & \multicolumn{2}{|c|}{$\begin{array}{c}60.39^{\star} \\
55.75-65.71 \\
\end{array}$} & $<0.001$ \\
\hline \multicolumn{18}{|c|}{ Probabilities of adequacy for SecDiet (0-1) } \\
\hline Vitamin A & 0.99 & 0.05 & 0.99 & 0.05 & 0.98 & 0.05 & 0.98 & 0.05 & 0.98 & 0.06 & 0.98 & 0.06 & 0.97 & 0.09 & 0.98 & 0.07 & - \\
\hline Thiamin & 1.00 & 0.00 & 1.00 & 0.00 & 1.00 & 0.00 & 1.00 & 0.00 & 1.00 & 0.00 & 1.00 & 0.00 & 1.00 & 0.00 & 1.00 & 0.00 & - \\
\hline Riboflavin & 0.98 & 0.09 & 0.98 & 0.10 & 0.97 & 0.10 & 0.97 & 0.11 & 0.96 & 0.12 & 0.95 & 0.14 & 0.93 & 0.17 & 0.95 & 0.15 & - \\
\hline Niacin & 1.00 & 0.02 & 1.00 & 0.02 & 1.00 & 0.01 & 1.00 & 0.01 & 1.00 & 0.02 & 1.00 & 0.03 & 1.00 & 0.03 & 1.00 & 0.03 & - \\
\hline Folate & 0.98 & 0.07 & 0.98 & 0.07 & 0.98 & 0.08 & 0.97 & 0.09 & 0.97 & 0.11 & 0.95 & 0.13 & 0.94 & 0.15 & 0.96 & 0.12 & - \\
\hline Vitamin B12 & 0.98 & 0.06 & 0.98 & 0.06 & 0.98 & 0.06 & 0.98 & 0.07 & 0.98 & 0.07 & 0.98 & 0.07 & 0.97 & 0.11 & 0.97 & 0.09 & - \\
\hline Vitamin C & 1.00 & 0.02 & 0.99 & 0.03 & 0.99 & 0.03 & 0.99 & 0.03 & 0.99 & 0.03 & 0.99 & 0.04 & 0.98 & 0.05 & 0.99 & 0.04 & - \\
\hline lodine & 0.90 & 0.16 & 0.89 & 0.17 & 0.88 & 0.18 & 0.88 & 0.19 & 0.86 & 0.20 & 0.84 & 0.22 & 0.81 & 0.25 & 0.84 & 0.22 & - \\
\hline Selenium & 1.00 & 0.02 & 1.00 & 0.02 & 1.00 & 0.01 & 1.00 & 0.02 & 1.00 & 0.02 & 1.00 & 0.02 & 1.00 & 0.03 & 1.00 & 0.02 & - \\
\hline Iron & 0.99 & 0.03 & 0.99 & 0.03 & 0.99 & 0.04 & 0.99 & 0.04 & 0.99 & 0.04 & 0.99 & 0.05 & 0.98 & 0.06 & 0.99 & 0.05 & - \\
\hline Zinc & 1.00 & 0.02 & 1.00 & 0.02 & 1.00 & 0.02 & 1.00 & 0.02 & 1.00 & 0.03 & 1.00 & 0.03 & 0.99 & 0.03 & 1.00 & 0.03 & - \\
\hline Calcium & 0.98 & 0.08 & 0.98 & 0.09 & 0.98 & 0.09 & 0.97 & 0.09 & 0.97 & 0.11 & 0.96 & 0.12 & 0.94 & 0.14 & 0.96 & 0.12 & - \\
\hline
\end{tabular}

* Significantly different from the reference (">3700€"), assessed by Dwass-Steel-Critchlow-Fligner (DSCF) test for pairwise multiple comparisons; significant at P<0.05. ${ }^{\dagger} \mathrm{P}$ for Kruskal-Wallis non-parametric test. 
Supplemental Table 4: The SecDiet score and its probabilities of adequacy according to professional situation in the French adult population from the INCA3 survey, $n=1,774$

\begin{tabular}{|c|c|c|c|c|c|c|c|}
\hline & \multicolumn{7}{|c|}{ Professional situation } \\
\hline & \multicolumn{2}{|c|}{$\begin{array}{c}\text { Other } \\
\text { occupations } \\
(n=1600)\end{array}$} & \multicolumn{2}{|c|}{$\begin{array}{c}\text { Unemployed } \\
\text { people } \\
(n=112)\end{array}$} & \multicolumn{2}{|c|}{$\begin{array}{l}\text { Students } \\
(n=62)\end{array}$} & \multirow[b]{2}{*}{$P^{\dagger}$} \\
\hline & Mean & $\mathrm{SD}$ & Mean & SD & Mean & SD & \\
\hline SecDiet (0-1) & 0.93 & 0.09 & 0.91 & 0.09 & 0.92 & 0.11 & \\
\hline $\begin{array}{l}\text { Median } \\
\text { Q1-Q3 }\end{array}$ & \multicolumn{2}{|c|}{$\begin{array}{c}0.97 \\
0.91-0.99 \\
\end{array}$} & \multicolumn{2}{|c|}{$\begin{array}{c}0.93^{\star} \\
0.86-0.98\end{array}$} & \multicolumn{2}{|c|}{$\begin{array}{c}0.95 \\
0.88-0.99\end{array}$} & $<0.001$ \\
\hline PANDiet (0-100) & 64.66 & 5.63 & 62.72 & 7.24 & 63.11 & 6.49 & \\
\hline $\begin{array}{l}\text { Median } \\
\text { Q1-Q3 }\end{array}$ & \multicolumn{2}{|c|}{$\begin{array}{c}64.92 \\
60.89-68.74\end{array}$} & \multicolumn{2}{|c|}{$\begin{array}{c}61.06^{\star} \\
59.06-66.92\end{array}$} & \multicolumn{2}{|c|}{$\begin{array}{c}64.36^{\star} \\
59.43-67.72\end{array}$} & $<0.001$ \\
\hline \multicolumn{8}{|c|}{ Probabilities of adequacy for SecDiet (0-1) } \\
\hline Vitamin A & 0.90 & 0.17 & 0.87 & 0.19 & 0.83 & 0.31 & - \\
\hline Thiamin & 1.00 & 0.01 & 1.00 & 0.01 & 1.00 & 0.01 & - \\
\hline Riboflavin & 0.94 & 0.12 & 0.94 & 0.10 & 0.92 & 0.14 & - \\
\hline Niacin & 1.00 & 0.01 & 1.00 & 0.01 & 1.00 & 0.00 & - \\
\hline Folate & 0.95 & 0.12 & 0.90 & 0.18 & 0.92 & 0.17 & - \\
\hline Vitamin B12 & 0.97 & 0.06 & 0.98 & 0.04 & 0.98 & 0.04 & - \\
\hline Vitamin C & 0.97 & 0.05 & 0.97 & 0.05 & 0.97 & 0.07 & - \\
\hline Iodine & 0.90 & 0.15 & 0.88 & 0.16 & 0.90 & 0.19 & - \\
\hline Selenium & 0.99 & 0.02 & 0.99 & 0.03 & 1.00 & 0.02 & - \\
\hline Iron & 0.96 & 0.07 & 0.96 & 0.06 & 0.98 & 0.04 & - \\
\hline Zinc & 0.98 & 0.05 & 0.99 & 0.03 & 0.99 & 0.02 & - \\
\hline Calcium & 0.94 & 0.12 & 0.89 & 0.24 & 0.92 & 0.20 & - \\
\hline
\end{tabular}


Supplemental Table 5: The SecDiet score and its probabilities of adequacy according to professional situation in the French adult population from the NutriNet-Santé study, n=104,382.

\begin{tabular}{|c|c|c|c|c|c|c|c|}
\hline & \multicolumn{7}{|c|}{ Professional situation } \\
\hline & \multicolumn{2}{|c|}{$\begin{array}{c}\text { Other } \\
\text { occupations } \\
(n=89238) \\
\end{array}$} & \multicolumn{2}{|c|}{$\begin{array}{c}\text { Unemployed } \\
\text { people } \\
(n=6371) \\
\end{array}$} & \multicolumn{2}{|c|}{$\begin{array}{l}\text { Students } \\
(\mathrm{n}=8773)\end{array}$} & \multirow[b]{2}{*}{$P^{\dagger}$} \\
\hline & Mean & SD & Mean & SD & Mean & SD & \\
\hline SecDiet (0-1) & 0.96 & 0.06 & 0.94 & 0.08 & 0.93 & 0.08 & \\
\hline $\begin{array}{l}\text { Median } \\
\text { Q1-Q3 }\end{array}$ & \multicolumn{2}{|c|}{$\begin{array}{c}0.98 \\
0.95-0.99\end{array}$} & \multicolumn{2}{|c|}{$\begin{array}{c}0.97^{\star} \\
0.93-0.99\end{array}$} & \multicolumn{2}{|c|}{$\begin{array}{c}0.97^{\star} \\
0.91-0.99\end{array}$} & $<0.001$ \\
\hline PANDiet (0-100) & 61.18 & 7.20 & 59.62 & 7.49 & 59.05 & 7.33 & \\
\hline $\begin{array}{l}\text { Median } \\
\text { Q1-Q3 }\end{array}$ & \multicolumn{2}{|c|}{$\begin{array}{c}60.58 \\
56.15-65.75 \\
\end{array}$} & \multicolumn{2}{|c|}{$\begin{array}{c}59.05^{*} \\
54.34-64.27 \\
\end{array}$} & \multicolumn{2}{|c|}{$\begin{array}{c}58.39^{*} \\
53.95-63.36 \\
\end{array}$} & $<0.001$ \\
\hline \multicolumn{8}{|c|}{ Probabilities of adequacy for SecDiet (0-1) } \\
\hline Vitamin A & 0.98 & 0.06 & 0.98 & 0.07 & 0.97 & 0.09 & - \\
\hline Thiamin & 1.00 & 0.00 & 1.00 & 0.01 & 1.00 & 0.00 & - \\
\hline Riboflavin & 0.97 & 0.11 & 0.95 & 0.15 & 0.92 & 0.18 & - \\
\hline Niacin & 1.00 & 0.02 & 1.00 & 0.03 & 1.00 & 0.03 & - \\
\hline Folate & 0.97 & 0.10 & 0.95 & 0.14 & 0.94 & 0.15 & - \\
\hline Vitamin B12 & 0.98 & 0.07 & 0.97 & 0.11 & 0.97 & 0.10 & - \\
\hline Vitamin C & 0.99 & 0.03 & 0.99 & 0.05 & 0.99 & 0.04 & - \\
\hline Iodine & 0.87 & 0.19 & 0.83 & 0.23 & 0.8 & 0.25 & - \\
\hline Selenium & 1.00 & 0.02 & 1.00 & 0.03 & 1.00 & 0.03 & - \\
\hline Iron & 0.99 & 0.04 & 0.98 & 0.05 & 0.98 & 0.06 & - \\
\hline Zinc & 1.00 & 0.02 & 1.00 & 0.03 & 0.99 & 0.04 & - \\
\hline Calcium & 0.97 & 0.10 & 0.95 & 0.13 & 0.95 & 0.14 & - \\
\hline
\end{tabular}


Supplemental Table 6: The SecDiet score and its probabilities of adequacy according to perception of financial situation in the French adult population from the INCA3 survey, $n=1,774$

\begin{tabular}{|c|c|c|c|c|c|c|c|c|c|c|c|c|c|c|c|}
\hline & \multicolumn{14}{|c|}{ Perception of financial situation } & \multirow[b]{3}{*}{$P^{\dagger}$} \\
\hline & \multicolumn{2}{|c|}{$\begin{array}{c}\text { Financially } \\
\text { comfortable } \\
(n=298)\end{array}$} & \multicolumn{2}{|c|}{$\begin{array}{l}\text { It's okay } \\
(n=663)\end{array}$} & \multicolumn{2}{|c|}{$\begin{array}{l}\text { It's tight } \\
(n=195)\end{array}$} & \multicolumn{2}{|c|}{$\begin{array}{c}\text { Manageable } \\
\text { if careful } \\
(n=496)\end{array}$} & \multicolumn{2}{|c|}{$\begin{array}{l}\text { Hard to make } \\
\text { ends meet } \\
(n=102)\end{array}$} & \multicolumn{2}{|c|}{$\begin{array}{l}\text { Can't manage } \\
\text { without debts } \\
(n=19)\end{array}$} & \multicolumn{2}{|c|}{$\begin{array}{l}\text { Refusal to } \\
\text { answer } \\
(n=1)\end{array}$} & \\
\hline & Mean & SD & Mean & SD & Mean & SD & Mean & SD & Mean & SD & Mean & SD & Mean & SD & \\
\hline SecDiet (0-1) & 0.94 & 0.08 & 0.94 & 0.06 & 0.92 & 0.09 & 0.92 & 0.10 & 0.89 & 0.14 & 0.85 & 0.14 & 0.96 & . & \multirow[b]{2}{*}{$<0.001$} \\
\hline $\begin{array}{l}\text { Median } \\
\text { Q1-Q3 }\end{array}$ & \multicolumn{2}{|c|}{$\begin{array}{c}0.97 \\
0.92-0.99 \\
\end{array}$} & \multicolumn{2}{|c|}{$\begin{array}{c}0.97 \\
0.92-0.99\end{array}$} & \multicolumn{2}{|c|}{$\begin{array}{c}0.96 \\
0.89-0.99 \\
\end{array}$} & \multicolumn{2}{|c|}{$\begin{array}{c}0.96 \\
0.89-0.99\end{array}$} & \multicolumn{2}{|c|}{$\begin{array}{c}0.93^{\star} \\
0.86-0.97\end{array}$} & \multicolumn{2}{|c|}{$\begin{array}{c}0.95^{\star} \\
0.81-0.97\end{array}$} & $\begin{array}{c}0.96 \\
-\end{array}$ & & \\
\hline PANDiet (0-100) & 65.31 & 5.19 & 64.56 & 5.40 & 64.26 & 5.18 & 64.09 & 6.23 & 63.55 & 8.00 & 63.36 & 7.55 & 54.25 & . & \multirow[b]{2}{*}{$<0.001$} \\
\hline $\begin{array}{l}\text { Median } \\
\text { Q1-Q3 }\end{array}$ & \multicolumn{2}{|c|}{$\begin{array}{c}65.16 \\
61.45-68.90 \\
\end{array}$} & \multicolumn{2}{|c|}{$\begin{array}{c}64.90 \\
60.27-68.62 \\
\end{array}$} & \multicolumn{2}{|c|}{$\begin{array}{c}64.19 \\
6.116-67.68 \\
\end{array}$} & \multicolumn{2}{|c|}{$\begin{array}{c}64.84 \\
60.06-68.27 \\
\end{array}$} & \multicolumn{2}{|c|}{$\begin{array}{c}63.12^{*} \\
59.16-67.53 \\
\end{array}$} & \multicolumn{2}{|c|}{$\begin{array}{c}62.05 \\
54.71-72.00 \\
\end{array}$} & $\begin{array}{r}54.25 \\
- \\
\end{array}$ & & \\
\hline \multicolumn{16}{|c|}{ Probabilities of adequacy for SecDiet (0-1) } \\
\hline Vitamin A & 0.92 & 0.17 & 0.92 & 0.14 & 0.86 & 0.23 & 0.89 & 0.18 & 0.82 & 0.27 & 0.82 & 0.18 & 0.96 & . & - \\
\hline Thiamin & 1.00 & 0.01 & 1.00 & 0.01 & 1.00 & 0.01 & 1.00 & 0.01 & 1.00 & 0.01 & 0.99 & 0.01 & 1.00 & . & - \\
\hline Riboflavin & 0.95 & 0.10 & 0.96 & 0.08 & 0.92 & 0.14 & 0.93 & 0.14 & 0.90 & 0.20 & 0.86 & 0.22 & 0.98 & . & - \\
\hline Niacin & 1.00 & 0.01 & 1.00 & 0.00 & 1.00 & 0.00 & 1.00 & 0.02 & 1.00 & 0.01 & 1.00 & 0.00 & 1.00 & . & - \\
\hline Folate & 0.94 & 0.14 & 0.96 & 0.08 & 0.95 & 0.09 & 0.93 & 0.14 & 0.90 & 0.22 & 0.84 & 0.18 & 0.95 & . & - \\
\hline Vitamin B12 & 0.97 & 0.06 & 0.98 & 0.04 & 0.97 & 0.05 & 0.97 & 0.06 & 0.96 & 0.08 & 0.94 & 0.11 & 1.00 & . & - \\
\hline Vitamin C & 0.98 & 0.04 & 0.98 & 0.04 & 0.98 & 0.04 & 0.97 & 0.06 & 0.95 & 0.07 & 0.91 & 0.19 & 0.96 & . & - \\
\hline Iodine & 0.90 & 0.18 & 0.91 & 0.14 & 0.91 & 0.13 & 0.90 & 0.15 & 0.87 & 0.20 & 0.80 & 0.19 & 0.96 & . & - \\
\hline Selenium & 0.99 & 0.01 & 0.99 & 0.02 & 0.99 & 0.02 & 0.99 & 0.02 & 0.98 & 0.04 & 0.98 & 0.03 & 1.00 & . & - \\
\hline Iron & 0.97 & 0.05 & 0.97 & 0.04 & 0.96 & 0.06 & 0.96 & 0.08 & 0.94 & 0.12 & 0.91 & 0.16 & 0.99 & . & - \\
\hline Zinc & 0.99 & 0.04 & 0.99 & 0.03 & 0.98 & 0.06 & 0.98 & 0.06 & 0.97 & 0.07 & 0.91 & 0.17 & 1.00 & . & - \\
\hline Calcium & 0.97 & 0.07 & 0.95 & 0.09 & 0.89 & 0.21 & 0.93 & 0.15 & 0.89 & 0.22 & 0.87 & 0.19 & 0.97 & . & - \\
\hline
\end{tabular}


Supplemental Table 7: The SecDiet score and its probabilities of adequacy according to food insufficiency status in the French adult population from the INCA3 survey, $n=1,774$

\begin{tabular}{|c|c|c|c|c|c|c|c|}
\hline & \multicolumn{7}{|c|}{ Food insufficiency status } \\
\hline & \multicolumn{2}{|c|}{$\begin{array}{c}\text { Food } \\
\text { sufficiency } \\
(n=1512)\end{array}$} & \multicolumn{2}{|c|}{$\begin{array}{c}\text { Qualitative } \\
\text { food } \\
\text { insufficiency } \\
(n=227) \\
\end{array}$} & \multicolumn{2}{|c|}{$\begin{array}{c}\text { Quantitative } \\
\text { food } \\
\text { sufficiency } \\
(n=35)\end{array}$} & \multirow[b]{2}{*}{$P^{\dagger}$} \\
\hline & Mean & SD & Mean & SD & Mean & SD & \\
\hline SecDiet (0-1) & 0.93 & 0.08 & 0.90 & 0.11 & 0.91 & 0.10 & \\
\hline $\begin{array}{l}\text { Median } \\
\text { Q1-Q3 }\end{array}$ & \multicolumn{2}{|c|}{$\begin{array}{c}0.97 \\
0.91-0.99\end{array}$} & \multicolumn{2}{|c|}{$\begin{array}{c}0.95^{\star} \\
0.87-0.98\end{array}$} & \multicolumn{2}{|c|}{$\begin{array}{c}0.95^{\star} \\
0.88-0.96\end{array}$} & $<0.001$ \\
\hline PANDiet (0-100) & 64.67 & 5.71 & 63.37 & 6.13 & 61.51 & 6.08 & \\
\hline $\begin{array}{l}\text { Median } \\
\text { Q1-Q3 }\end{array}$ & \multicolumn{2}{|c|}{$\begin{array}{c}64.92 \\
60.95-68.63\end{array}$} & \multicolumn{2}{|c|}{$\begin{array}{c}62.59 * \\
59.23-67.96 \\
\end{array}$} & \multicolumn{2}{|c|}{$\begin{array}{c}61.43^{*} \\
56.87-66.84\end{array}$} & $<0.001$ \\
\hline \multicolumn{8}{|c|}{ Probabilities of adequacy for SecDiet (0-1) } \\
\hline Vitamin A & 0.90 & 0.17 & 0.84 & 0.24 & 0.90 & 0.14 & - \\
\hline Thiamin & 1.00 & 0.01 & 1.00 & 0.01 & 1.00 & 0.01 & - \\
\hline Riboflavin & 0.95 & 0.12 & 0.91 & 0.17 & 0.93 & 0.12 & - \\
\hline Niacin & 1.00 & 0.01 & 1.00 & 0.01 & 1.00 & 0.00 & - \\
\hline Folate & 0.94 & 0.12 & 0.92 & 0.16 & 0.93 & 0.17 & - \\
\hline Vitamin B12 & 0.97 & 0.05 & 0.96 & 0.07 & 0.97 & 0.05 & - \\
\hline Vitamin C & 0.98 & 0.05 & 0.97 & 0.05 & 0.92 & 0.15 & - \\
\hline Iodine & 0.90 & 0.15 & 0.89 & 0.15 & 0.89 & 0.18 & - \\
\hline Selenium & 0.99 & 0.02 & 0.99 & 0.03 & 1.00 & 0.02 & - \\
\hline Iron & 0.97 & 0.06 & 0.95 & 0.11 & 0.94 & 0.11 & - \\
\hline Zinc & 0.99 & 0.05 & 0.98 & 0.07 & 0.98 & 0.07 & - \\
\hline Calcium & 0.94 & 0.12 & 0.90 & 0.21 & 0.94 & 0.12 & - \\
\hline
\end{tabular}


Supplemental Table 8: The SecDiet score and its probabilities of adequacy according to food security status in the French adult population from the INCA3 survey, $n=1,774$.

\begin{tabular}{|c|c|c|c|c|c|c|c|}
\hline & \multicolumn{7}{|c|}{ Food security status } \\
\hline & \multicolumn{2}{|c|}{$\begin{array}{c}\text { Food } \\
\text { security } \\
(n=1654)\end{array}$} & \multicolumn{2}{|c|}{$\begin{array}{l}\text { Moderate } \\
\text { food } \\
\text { insecurity } \\
(n=73)\end{array}$} & \multicolumn{2}{|c|}{$\begin{array}{l}\text { Severe food } \\
\text { insecurity } \\
\quad(n=47)\end{array}$} & \multirow[b]{2}{*}{$P^{1}$} \\
\hline & Mean & SD & Mean & SD & Mean & SD & \\
\hline SecDiet (0-1) & 0.93 & 0.08 & 0.89 & 0.13 & 0.89 & 0.10 & \\
\hline $\begin{array}{l}\text { Median } \\
\text { Q1-Q3 }\end{array}$ & \multicolumn{2}{|c|}{$\begin{array}{c}0.97 \\
0.91-0.99 \\
\end{array}$} & \multicolumn{2}{|c|}{$\begin{array}{c}0.94^{*} \\
0.82-0.99\end{array}$} & \multicolumn{2}{|c|}{$\begin{array}{c}0.89 * \\
0.88-0.95\end{array}$} & $<0.001$ \\
\hline PANDiet (0-100) & 64.53 & 5.73 & 63.07 & 6.00 & 62.72 & 7.28 & \\
\hline $\begin{array}{l}\text { Median } \\
\text { Q1-Q3 }\end{array}$ & $\begin{array}{r}64 \\
60.61 \\
\end{array}$ & $\begin{array}{l}4 \\
8.58 \\
\end{array}$ & $\begin{array}{r}61 . \\
58.58 \\
\end{array}$ & $\begin{array}{l}* \\
7.69 \\
\end{array}$ & $\begin{array}{r}60 . \\
57.30-\end{array}$ & $\begin{array}{l}8 \\
7.02 \\
\end{array}$ & 0.002 \\
\hline \multicolumn{8}{|c|}{ Probabilities of adequacy for SecDiet (0-1) } \\
\hline Vitamin A & 0.90 & 0.18 & 0.84 & 0.24 & 0.81 & 0.19 & - \\
\hline Thiamin & 1.00 & 0.01 & 1.00 & 0.01 & 1.00 & 0.01 & - \\
\hline Riboflavin & 0.95 & 0.12 & 0.90 & 0.17 & 0.91 & 0.12 & - \\
\hline Niacin & 1.00 & 0.01 & 1.00 & 0.01 & 1.00 & 0.01 & - \\
\hline Folate & 0.94 & 0.12 & 0.89 & 0.22 & 0.91 & 0.15 & - \\
\hline Vitamin B12 & 0.97 & 0.05 & 0.96 & 0.06 & 0.98 & 0.05 & - \\
\hline Vitamin C & 0.97 & 0.05 & 0.96 & 0.05 & 0.95 & 0.13 & - \\
\hline Iodine & 0.90 & 0.15 & 0.88 & 0.16 & 0.88 & 0.17 & - \\
\hline Selenium & 0.99 & 0.02 & 0.98 & 0.05 & 0.99 & 0.02 & - \\
\hline Iron & 0.97 & 0.06 & 0.93 & 0.11 & 0.95 & 0.11 & - \\
\hline Zinc & 0.99 & 0.05 & 0.97 & 0.05 & 0.97 & 0.11 & - \\
\hline Calcium & 0.94 & 0.14 & 0.92 & 0.15 & 0.91 & 0.13 & - \\
\hline
\end{tabular}




\section{Supplemental References}

1. EFSA (European Food Safety Agency) (2017) Dietary Reference Values for nutrients: Summary report. 92.

2. Otten JJ, Hellwig JP \& Meyers LD (editors) (2006) DRI, dietary reference intakes: the essential guide to nutrient requirements. Washington, D.C: National Academies Press.

3. Anses (2016) Actualisation des repères du PNNS : élaboration des références nutritionnelles. Maisons-Alfort, France: French Agency for Food, Environmental and Occupational Health Safety (Anses).

4. World Health Organization \& Food and Agriculture Organization of the United Nations (editors) (2004) Vitamin and mineral requirements in human nutrition. 2nd ed. Geneva : Rome: World Health Organization; FAO.

5. Nordic Council of Ministers (2014) Nordic Nutrition Recommendations 2012: Integrating nutrition and physical activity. Copenhagen: Nordic Council of Ministers.

6. Wémeau J-L (2010) Chapitre 8. Goitres simples et nodulaires. In Les maladies de la thyroïde. Masson.

7. World Health Organization, Food and Agriculture Organization of the United Nations \& International Atomic Energy Agency (editors) (1996) Trace elements in human nutrition and health. Geneva: World Health Organization.

8. de Gavelle E, Huneau J-F \& Mariotti F (2018) Patterns of Protein Food Intake Are Associated with Nutrient Adequacy in the General French Adult Population. Nutrients 10, 226.

9. Equipe de Surveillance et d'épidémiologie nutritionnelle (ESEN) (2019) Étude de santé sur l'environnement, la biosurveillance, l'activité physique et la nutrition (Esteban), 2014-2016. Volet Nutrition. Chapitre Dosages biologiques : vitamines et minéraux. Saint-Maurice, France: Santé Publique France.

10. Armah SM, Carriquiry A, Sullivan D, et al. (2013) A Complete Diet-Based Algorithm for Predicting Nonheme Iron Absorption in Adults. The Journal of Nutrition 143, 1136-1140.

11. Hallberg L \& Hulthén L (2000) Prediction of dietary iron absorption: an algorithm for calculating absorption and bioavailability of dietary iron. The American Journal of Clinical Nutrition 71, 1147-1160.

12. Biesalski HK \& Grimm P (2005) Pocket atlas of nutrition. Rev. translation of 3rd German ed. Stuttgart ; New York: Thieme.

13. Institute of Medicine (U.S.) \& Panel on Micronutrients (2002) Dietary reference intakes for vitamin $A$, vitamin $K$, arsenic, boron, chromium, copper, iodine, iron, manganese, molybdenum, nickel, silicon, vanadium, and zinc. Washington, D.C.: National Academy Press.

14. Miller LV, Krebs NF \& Hambidge KM (2007) A Mathematical Model of Zinc Absorption in Humans As a Function of Dietary Zinc and Phytate. The Journal of Nutrition 137, 135-141. 
15. Wang D, Chen X-H, Fu G, et al. (2015) Calcium intake and hip fracture risk: a metaanalysis of prospective cohort studies. Int J Clin Exp Med.

16. Bolland $M J$, Leung $W$, Tai $V$, et al. (2015) Calcium intake and risk of fracture: systematic review. $B M J, \mathrm{~h} 4580$.

17. Bischoff-Ferrari HA, Dawson-Hughes B, Baron JA, et al. (2007) Calcium intake and hip fracture risk in men and women: a meta- analysis of prospective cohort studies and randomized controlled trials1-3. Am J Clin Nutr.

18. Gletsu-Miller N \& Wright BN (2013) Mineral Malnutrition Following Bariatric Surgery. Advances in Nutrition 4, 506-517.

19. EFSA NDA Panel (EFSA Panel on Nutrition, Novel Foods and Food Allergens) (2019) Scientific Opinion on the dietary reference values for sodium. EFSA Journal.

20. Verger EO, Mariotti F, Holmes BA, et al. (2012) Evaluation of a Diet Quality Index Based on the Probability of Adequate Nutrient Intake (PANDiet) Using National French and US Dietary Surveys. PLoS ONE 7, e42155 [Cameron DW, editor].

21. de Gavelle E, Huneau J-F, Fouillet H, et al. (2019) The Initial Dietary Pattern Should Be Considered when Changing Protein Food Portion Sizes to Increase Nutrient Adequacy in French Adults. The Journal of Nutrition 149, 488-496.

22. Food and Agriculture Organization of the United Nations (editor) (2013) Dietary protein quality evaluation in human nutrition: report of an FAO expert consultation, 31 March-2 April, 2011, Auckland, New Zealand. Rome: Food and Agriculture Organization of the United Nations.

23. Anses (2019) Anses Opinion on the updating of the PNNS dietary guidelines for women from menopause and men over 65 years of age. Maisons-Alfort, France: French Agency for Food, Environmental and Occupational Health Safety (Anses).

24. Anses (2011) Actualisation des apports nutritionnels conseillés pour les acides gras. Maisons-Alfort, France: French Agency for Food, Environmental and Occupational Health Safety (Anses).

25. EFSA NDA Panel (EFSA Panel on Nutrition, Novel Foods and Food Allergens) (2016) Scientific opinion on Dietary Reference Values for vitamin B6. EFSA Journal. 